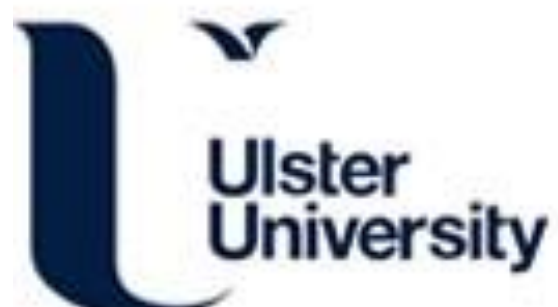

\section{Acetylene-argon plasmas measured at a biased substrate electrode for diamond-like carbon deposition: I. Mass spectrometry}

Baby, A., Mahony, CMO., \& Maguire, PD. (2011). Acetylene-argon plasmas measured at a biased substrate electrode for diamond-like carbon deposition: I. Mass spectrometry. Plasma Sources Science and Technology, 20(015003). https://doi.org/10.1088/0963-0252/20/1/015003

Link to publication record in Ulster University Research Portal

\section{Published in:}

Plasma Sources Science and Technology

Publication Status:

Published (in print/issue): 07/01/2011

DOI:

10.1088/0963-0252/20/1/015003

\section{Document Version}

Publisher's PDF, also known as Version of record

\section{General rights}

Copyright for the publications made accessible via Ulster University's Research Portal is retained by the author(s) and / or other copyright owners and it is a condition of accessing these publications that users recognise and abide by the legal requirements associated with these rights.

\section{Take down policy}

The Research Portal is Ulster University's institutional repository that provides access to Ulster's research outputs. Every effort has been made to ensure that content in the Research Portal does not infringe any person's rights, or applicable UK laws. If you discover content in the Research Portal that you believe breaches copyright or violates any law, please contact pure-support@ulster.ac.uk. 
Acetylene-argon plasmas measured at a biased substrate electrode for diamond-like carbon deposition: I. Mass spectrometry

This article has been downloaded from IOPscience. Please scroll down to see the full text article.

2011 Plasma Sources Sci. Technol. 20015003

(http://iopscience.iop.org/0963-0252/20/1/015003)

View the table of contents for this issue, or go to the journal homepage for more

Download details:

IP Address: 194.80.87.141

The article was downloaded on 25/03/2011 at 13:35

Please note that terms and conditions apply. 


\title{
Acetylene-argon plasmas measured at a biased substrate electrode for diamond-like carbon deposition: I. Mass spectrometry*
}

\author{
A Baby, C M O Mahony and P D Maguire \\ Nanotechnology and Integrated Bio-Engineering Centre (NIBEC), University of Ulster, Newtownabbey, \\ BT37 0QB, UK \\ E-mail: pd.maguire@ulster.ac.uk
}

Received 25 November 2008, in final form 24 July 2010

Published 7 January 2011

Online at stacks.iop.org/PSST/20/015003

\begin{abstract}
We report, for the first time, quadrupole mass spectrometry of neutral and positive ionic hydrocarbon species measured at the rf-biased substrate electrode of an inductively coupled plasma for acetylene rich $\mathrm{C}_{2} \mathrm{H}_{2}$ : Ar mixtures under various bias, frequency and pressure conditions. It has been observed that, irrespective of initial gas mixture, the resultant plasma is dominated by argon neutrals and ions. This is attributed to highly efficient conversion of acetylene to $\mathrm{C}_{2} \mathrm{H}$ due to the enhanced electron density compared with a standard capacitive plasma where the acetylene (neutral and ion) species remain dominant. This conversion may be crucial to film formation via inert rather than hydrocarbon ion bombardment. In addition, the transient formation of $\mathrm{CH}_{4}$ from acetylene has been discovered using IR absorption spectroscopy with time constants similar to observed pressure variations. Rate coefficients and rates for many of the reaction mechanisms, calculated using measured electron energy distribution functions and species densities, are given. These results have important application in plasma models and growth studies for hydrogenated amorphous or diamond-like carbon film deposition. Film growth under similar plasma conditions is reported in an associated paper along with ion energy distributions for important growth species.

(Some figures in this article are in colour only in the electronic version)
\end{abstract}

\section{Introduction}

Diamond-like or amorphous carbons (DLC), particularly hydrogenated amorphous carbon $(\mathrm{a}-\mathrm{C}: \mathrm{H})$, represent a class of technologically important thin film materials. The ability to vary properties, such as hardness, Young's modulus, surface roughness, electrical resistance, thermal conductivity, density, refractive index, offers considerable versatility in mechanical, electrical, optical and more recently biomedical applications [1]. These films are routinely deposited from hydrocarbon precursors, particularly $\mathrm{C}_{2} \mathrm{H}_{2}$, in conventional radio frequency (rf) capacitively coupled plasma (CCP) systems [2-8],

* This paper was presented as an invited talk at the 19th European Sectional Conference on Atomic and Molecular Physics of Ionized Gases, Granada, Spain, 15-19 July 2008. See stacks.iop.org/PSST/18/3. expanding thermal plasma $[9,10]$ and to a limited extent from inductively coupled plasma (ICP) systems [11-13]. These studies focussed mainly on material properties' dependence on the key input variables, e.g. chamber pressure, power, flow rate, etc. However, future applications, for example in the biomedical arena, will require deposition at higher pressures or onto complex three-dimensional shapes. Hence a much greater understanding of film growth mechanisms which in turn depend on plasma-substrate conditions is necessary.

The growth of hydrogen-free DLC (tetragonal amorphous carbon, t-aC) is well understood in terms of carbon ion bombardment as the dominant species and sub-plantation or incorporation of the carbon into the growing film [14-16]. However, hydrogenated DLC $(\mathrm{a}-\mathrm{C}: \mathrm{H})$ has greater potential application, yet its growth mechanism is highly complex 
and as yet not understood [17]. A critical impediment is the lack of knowledge of substrate bombardment species, their energies and fluxes, from hydrocarbon-based plasmas, particularly acetylene, which is the preferred precursor gas over methane $[4,16]$. There has been some attention given to gas-phase species and reactions in methane containing plasmas $[2,11,13,18,19]$ and to a much more limited extent to pure acetylene plasmas [20-23] for understanding polymerization reactions, nanoparticle (dust) growth and DLC film formation. Vasile and Smolinsky [23] examined by mass spectrometry the ion chemistry of a pure and mixed acetylene discharges to determine the major reaction paths and highlight the main neutral-neutral and ion-neutral reactions. In their work on dusty plasmas, Deschenaux et al [20] studied mass and energy spectra of dominant ions and neutrals in methane, acetylene and ethylene plasmas. Macek and Cekada [24] used mass-energy spectrometry of $\mathrm{C}_{2} \mathrm{H}_{2} / \mathrm{Ar}$ in a triode ion plating apparatus and revealed a high degree of acetylene decomposition. However, the spectra were complicated by the presence of Ti species from an in situ evaporation source. Rangel et al [25] studied the electrical and optical properties of a polymerizing $\mathrm{C}_{2} \mathrm{H}_{2} / \mathrm{Ar}$ plasma where OES was used to study mainly $\mathrm{H}$ and $\mathrm{CH}$ neutral species. Doyle [22] compared the kinetics of a methane rf glow discharge with measured gas species production and depletion rates in pure acetylene discharges. One-dimensional fluid models for pure acetylene plasmas were developed by De Bleecker et al [21] and Herrebout et al [26] in order to understand the basic electron impact, ion-neutral and neutral-neutral reactions underlying the growth of nanosized (or dust) particles. Other models include a zero-dimension kinetic model [27] of a $\mathrm{rf}_{2} \mathrm{H}_{2}$ $(1 \%) / \mathrm{H}_{2} /$ Ar-rich plasma to determine the influence of pressure and power in the synthesis of nanodiamond thin films.

The existing experimental data and models of $\mathrm{C}_{2} \mathrm{H}_{2}$-based plasma species have provided a framework for understanding the complex gas-phase reactions; however, their applicability to film growth conditions is much less appropriate. Typical deposition pressures are much lower (<10 mTorr) than reported to date and high quality film growth normally requires $\mathrm{C}_{2} \mathrm{H}_{2}$ dilution with 30-90\% inert gas (Ar). More importantly, the competing growth/etch mechanisms depend upon complex synergistic interactions between bombarding ions, radicals and the dynamic film surface [17]. Therefore, greater insight requires direct measurement of species flux and energy at the substrate under realistic growth conditions. Studies have been undertaken to measure substrate bombarding species using retarding field analysers, but mainly in etch gases [28-30]. However, mass resolution is not possible with this configuration. Mass and ion energy (IE) spectrometry has been reported for $\mathrm{CF}_{4}$ plasmas [31] and for a $\mathrm{CH}_{4}$ ECR source [32]. However, in neither case was the spectrometer located at the biased substrate electrode and thus the energies of growth/etch species could not be accurately determined.

In this paper we present ion and neutral species flux measurements obtained at the biased substrate under low pressure deposition conditions in a $\mathrm{C}_{2} \mathrm{H}_{2}$ : Ar plasma. Two standard plasma systems were investigated, namely a CCP and an ICP discharge. The former has been in routine use for the production of DLC films [1,4-7, 16] and has been modified (increased chamber height) to accept a port for attachment of the mass-energy spectrometer to the chamber wall. The ICP system has been custom-designed to accommodate a range of optical and electrical diagnostics, including the incorporation of the mass-energy analyser (MEA) into the rf-biased sample substrate. Additional diagnostics in the ICP system include a Langmuir probe, optical emission spectroscopy and quantum-cascade laser infrared absorption spectroscopy for the determination of the dominant neutral species in the bulk plasma. In a second companion paper [33], we present massresolved ion energy distribution (IED) spectra under a range of low pressure plasma conditions for direct comparison with deposited DLC film quality. Deposited film properties are evaluated under a range of conditions in order to derive guiding principles for process optimization in terms of mean IE, IE spread and temporal neutral evolution and their relationship to bias voltage and frequency, pressure and gas flow ratio. In addition we also present some high pressure data for species flux and film growth.

The measurements of neutral and positive ionic species are first presented for $\mathrm{C}_{2} \mathrm{H}_{2}$ : Ar as the working gas. A complex network of reaction paths can be expected under our plasma conditions. However, we consider our observed species fluxes in terms of the simplest plausible reaction paths in order to highlight areas worthy of more detailed study. The formation of negative ions is also likely [20] but here we focus particularly on electropositive species and neutrals most favourable for DLC growth.

\section{Experimental details}

The measurements described in this study were performed in two rf driven plasma facilities, one employing a CCP and the other an ICP. The working gases were usually pure argon or $2: 1 \mathrm{C}_{2} \mathrm{H}_{2}$ : Ar mixtures; the small number of measurements made with other flow ratios are noted in the text.

\subsection{Capacitively coupled plasma}

The CCP comprised a $360 \mathrm{~mm}$ diameter $480 \mathrm{~mm}$ tall cylindrical chamber attached to associated gas, vacuum and electrical supplies. Gas flow controllers were used to set the flow rates (and thus ratios) of the working gases over the pressure range studied. A $13.56 \mathrm{MHz}$ rf power supply and matching network were used to apply an rf potential to the $270 \mathrm{~m}$ diameter driven (substrate) electrode, sited centrally at the base of the chamber. To measure neutral fluxes, ion fluxes and energies, the chamber was adapted to house a HIDEN EQP 300 MEA, which was sited at the side wall of the chamber, $170 \mathrm{~mm}$ above the top face of the driven electrode. The MEA was operated in three analysis modes: neutral mass (NM) for the mass-resolved neutral flux, ion mass (IM) for mass-resolved positive ion flux and IE to give the IED. These measurements were made for pressures 2 to 33 mTorr and negative CCP dc bias $\left(V_{\mathrm{dc}}\right)$ voltages of 0 to $475 \mathrm{~V}$. The upper limit of $V_{\mathrm{dc}}$ represents an input power of $\sim 130 \mathrm{~W}$. 


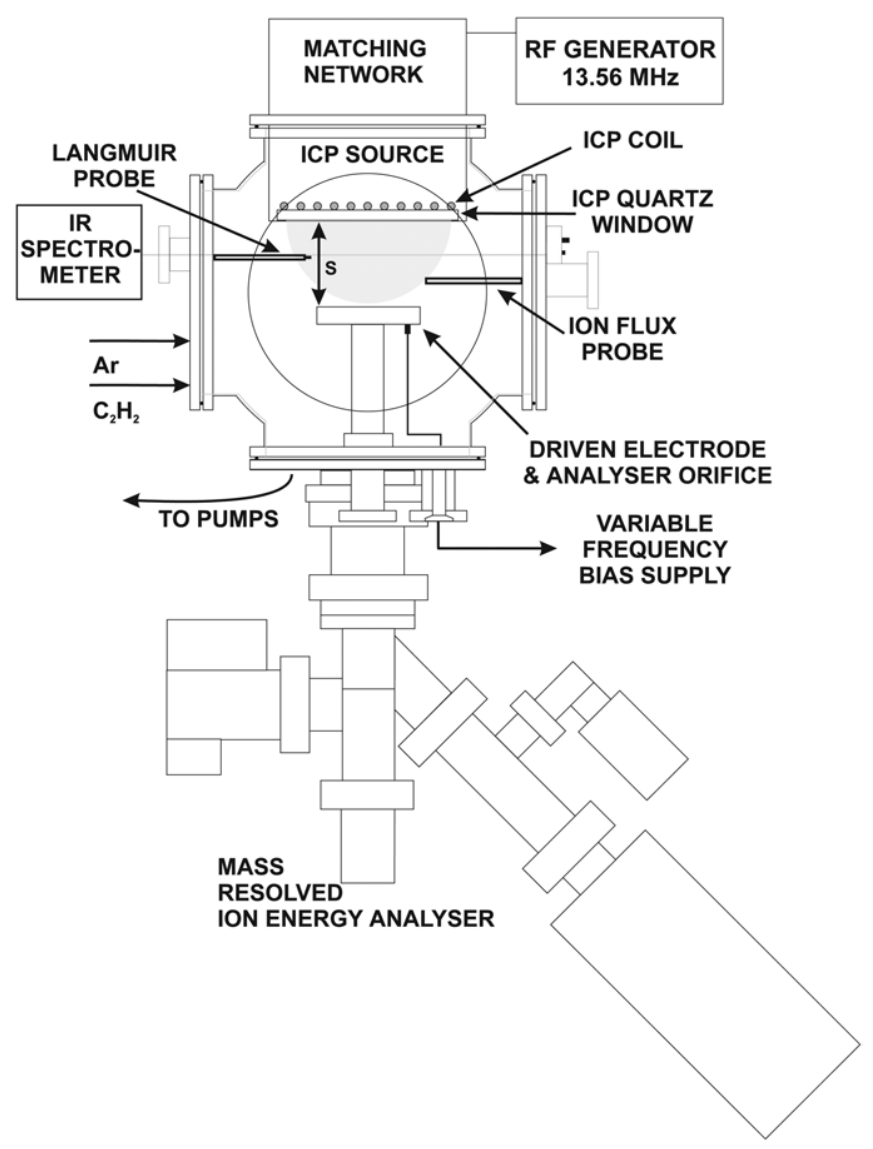

Figure 1. ICP chamber and diagnostics schematic diagram.

\subsection{Inductively coupled plasma}

The ICP chamber (figure 1) is a $400 \mathrm{~mm}$ diameter sphere with six orthogonal $250 \mathrm{~mm}$ diameter ports which provide access for plasma systems and diagnostics. Needle valves were used to set the flow rates and ratios of the working gases within a pressure range $3.3-120$ mTorr. The $13.56 \mathrm{MHz}$ rf power supply and close coupled automatic matching network drive an rf current through the water cooled $152 \mathrm{~mm}$ diameter flat spiral ICP coil, which has four lobes to inhibit E-mode operation. The oscillating rf current in the coil couples to the plasma via a $12.5 \mathrm{~mm}$ thick quartz vacuum window below which a $120 \mathrm{~mm}$ diameter substrate electrode is sited. The window to electrode separation was $160 \mathrm{~mm}$ for all measurements. A second, variable frequency $\left(f_{\text {bias }}\right)$, rf power supply and matching network was used to apply a negative bias $\left(V_{\text {bias }}\right)$ to the substrate electrode. The substrate electrode was coupled, via a central $50 \mu \mathrm{m}$ diameter hole, to the MEA, which was again operated in NM, IM and IE modes. Infrared absorption spectroscopy was used to measure line integrated species densities of $\mathrm{CH}_{4}$ and $\mathrm{C}_{2} \mathrm{H}_{2}$ using a NeoPlas QCL-MACS system with a multi-pass White-cell arrangement [34]. The measurement axis crossed the vertical plasma axis $110 \mathrm{~mm}$ above the substrate electrode. A Scientific Systems compensated Langmuir probe was used to measure electron energy distribution functions (EEDFs), number densities, electron temperature, plasma and floating potentials $107 \mathrm{~mm}$ above the bias electrode, at a radius of $45 \mathrm{~mm}$ from the vertical axis. In house analysis was used to determine the component distributions of the measured EEDFs. A Scientific Systems ion flux probe (IFP) was used to measure the total positive ion flux at the side of the plasma $50 \mathrm{~mm}$ above the bias electrode and $145 \mathrm{~mm}$ from the axis. This study concentrates on the abundance of neutral and positive ion species with varying pressure, $V_{\text {bias }}$ and $f_{\text {bias. }}$. In most cases the ICP input power was set at $200 \mathrm{~W}$ and automatically matched so that the reflected power was $<1 \mathrm{~W}$. The working gases were again pure argon or $2: 1 \mathrm{C}_{2} \mathrm{H}_{2}:$ Ar.

\section{Results}

We present data for both neutral and positive ion species in the CCP and ICP discharge systems described above. We do not consider negative ions because the negative ion flux from the plasma is assumed to be insignificant due to trapping in the positive plasma potential. Species identification is usually straightforward; however, it is worth noting that although we assign $\mathrm{C}_{2} \mathrm{H}_{4}$ to mass 28 this peak is liable to masking by $\mathrm{N}_{2}$ or CO. In addition, $\mathrm{C}_{2} \mathrm{H}_{6}$ has been assigned to mass 30 although a contribution by $\mathrm{NO}$ is also possible.

For all $\mathrm{C}_{2} \mathrm{H}_{2}$ : Ar gas mixtures in both $\mathrm{CCP}$ and ICP systems, the set chamber pressure decreased after plasma turnon. For $475 \mathrm{~V} V_{\mathrm{dc}} \mathrm{CCP}$ discharges with an initial $\mathrm{C}_{2} \mathrm{H}_{2}$ : $\mathrm{Ar}$ flow ratio of $2: 1$, the pressure typically reduced to $73 \%$ of the set pressure. In the ICP discharges, for $200 \mathrm{~W}$ rf power, the pressure approaches the argon partial pressure, with typical time constants around 3 to $10 \mathrm{~s}$, depending on set pressure. The pressure values quoted here are the equilibrium 'plasmaon' values: gas flow ratios, however, are those set beforehand, i.e. for 'plasma-off' pressures.

\subsection{CCP neutrals}

Figure 2 shows the count rate of a set of neutral species normalized to pressure and plotted as a function of pressure for a $\mathrm{C}_{2} \mathrm{H}_{2}$ : Ar mixture (flow ratio $2: 1$ ) in the CCP system described in section 2. The MEA was mounted on the grounded chamber wall and operated in NM mode. We observe two distinct sets of species, one whose normalized count rate is constant with pressure; this includes atoms $\left(\mathrm{Ar}, \mathrm{C}, \mathrm{H}, \mathrm{Ar}^{2+}\right)$, molecules $\left(\mathrm{C}_{2} \mathrm{H}_{2}, \mathrm{C}_{2} \mathrm{H}_{4}, \mathrm{C}_{4} \mathrm{H}_{2}\right)$ and radicals $\left(\mathrm{C}_{2} \mathrm{H}, \mathrm{C}_{2}, \mathrm{C}_{2} \mathrm{H}_{3}\right.$, $\mathrm{CH}, \mathrm{CH}_{3}$ and $\left.\mathrm{C}_{4} \mathrm{H}_{4}\right)$, figure $2(a)$. The average ratio across this pressure range (shown in parenthesis) is calculated with respect to that of argon and shows the dominance of the ethyl $\left(\mathrm{C}_{2} \mathrm{H}\right)$ radical while the methyl $\left(\mathrm{CH}_{3}\right)$ radical was found to have almost the lowest concentration in this set, just above $\mathrm{C}_{4} \mathrm{H}_{4}$, the heaviest observed species. Other hydrocarbon species $\mathrm{C}_{x} \mathrm{H}_{y}$ ( $x=1$ to $4, y=0$ to 4 ) in addition to $\mathrm{Ar}^{2+}$ were found to be of intermediate concentration. The second set consists of the remaining species, namely $\mathrm{H}_{2} \mathrm{O}, \mathrm{OH}, \mathrm{CO}_{2}$ and $\mathrm{ArH}$. Their normalized count rates decreased with increasing pressure, figure $2(b)$, with almost identical trends. The dominant species in this set, $\mathrm{H}_{2} \mathrm{O}$, has a similar concentration to $\mathrm{C}_{2} \mathrm{H}$ at low pressure. 

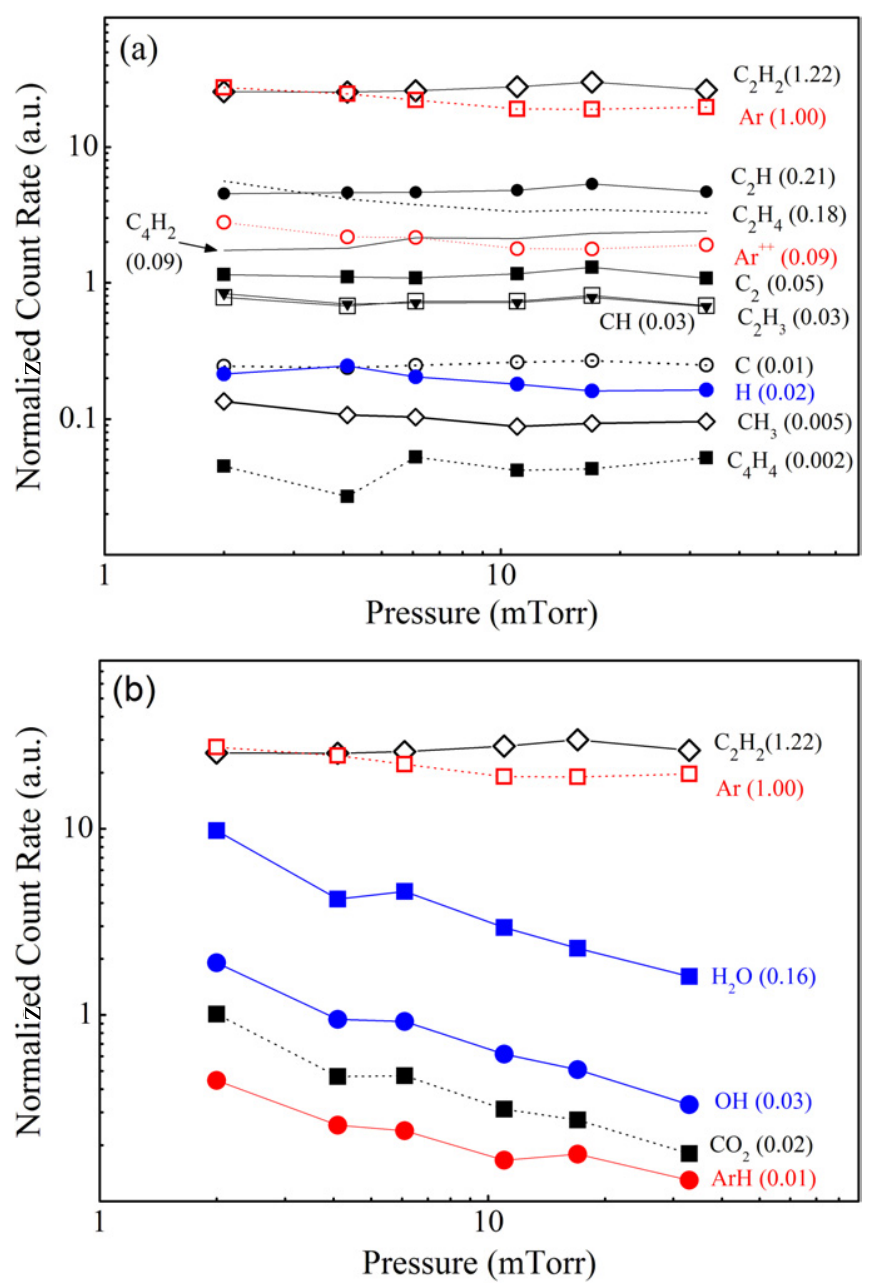

Figure 2. Normalized count rate of neutral species in $\mathrm{C}_{2} \mathrm{H}_{2}$ : $\mathrm{Ar}$ (flow ratio 2:1) CCP versus pressure at $V_{\mathrm{dc}}=450 \mathrm{~V}$ and $f=13.56 \mathrm{MHz}$. The ratios with respect to the argon value are shown in parentheses. (a) Species with little variation with pressure. (b) Species which fall with pressure. Count rates for plasma-off conditions are shown as $V_{\mathrm{dc}}=0 \mathrm{~V}$ in figure 5 .

\subsection{CCP positive ions}

Positive ion count rates were obtained in IM mode with the spectrometer attached to the grounded chamber wall and scanned over the mass range $0-60 \mathrm{amu}$ at an IE of $30 \mathrm{eV}$, chosen so as to prevent count saturation. Figure 3 shows a typical contribution of positive ions to the mass flux for a fixed pressure (6 mTorr), $\mathrm{C}_{2} \mathrm{H}_{2}:$ Ar mixture (flow ratio $2: 1$ ) and $450 \mathrm{~V}$ substrate bias. The dominant ion species are $\mathrm{C}_{2} \mathrm{H}_{2}^{+}$, followed by $\mathrm{Ar}^{+}, \mathrm{C}_{4} \mathrm{H}_{2}^{+}$and $\mathrm{C}_{4} \mathrm{H}_{3}^{+}$. Other significant species include $\mathrm{C}_{2} \mathrm{H}^{+}, \mathrm{H}_{2}^{+}, \mathrm{H}_{3}^{+}, \mathrm{C}_{2}^{+}, \mathrm{C}_{2} \mathrm{H}_{3}^{+}$and $\mathrm{C}_{2} \mathrm{H}_{4}^{+}$. Among the heavier mass ions, $\mathrm{C}_{4} \mathrm{H}^{+}, \mathrm{C}_{4} \mathrm{H}_{4}^{+}$and $\mathrm{C}_{4} \mathrm{H}_{5}^{+}$are also abundant.

Since direct quantitative comparison of neutral and ion count rates is not possible due to the different sensitivities in NM and IM modes, we compare relative fluxes by first normalizing them to their respective argon count rate, figure 4. For some species the normalized neutral count is greater than that of its ion: $\mathrm{OH}, \mathrm{H}_{2} \mathrm{O}, \mathrm{Ar}^{2+}, \mathrm{C}_{2} \mathrm{H}_{4}, \mathrm{C}_{3}$ and $\mathrm{CO}_{2}$. For others the converse is the case: $\mathrm{H}^{+}, \mathrm{H}_{2}^{+}, \mathrm{C}_{2} \mathrm{H}_{2}^{+}, \mathrm{C}_{2} \mathrm{H}_{3}^{+}, \mathrm{C}_{3} \mathrm{H}^{+}, \mathrm{C}_{3} \mathrm{H}_{3}^{+}$, $\mathrm{ArH}^{+}, \mathrm{C}_{4} \mathrm{H}^{+}, \mathrm{C}_{4} \mathrm{H}_{2}^{+}, \mathrm{C}_{4} \mathrm{H}_{3}^{+}, \mathrm{C}_{4} \mathrm{H}_{4}^{+}, \mathrm{C}_{4} \mathrm{H}_{5}^{+}$. Similar normalized

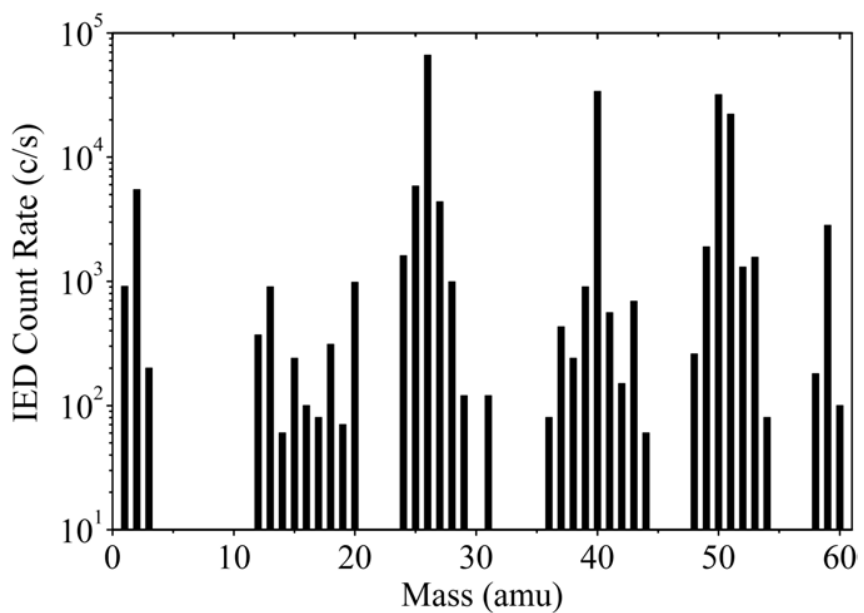

Figure 3. IM spectrum rate in the CCP: 6 mTorr $\mathrm{C}_{2} \mathrm{H}_{2}$ : Ar (flow ratio $2: 1)$ at $V_{\mathrm{dc}}=450 \mathrm{~V}$ and $f=13.56 \mathrm{MHz}$. The IE was set at $30 \mathrm{eV}$ to avoid saturation.

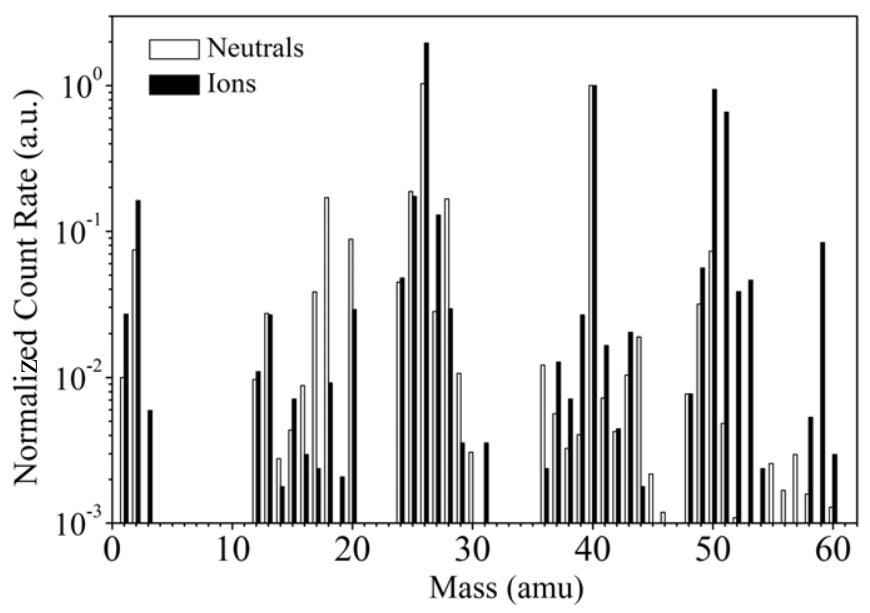

Figure 4. Neutral and IM spectra normalized with respect to argon in the CCP: 6 mTorr $\mathrm{C}_{2} \mathrm{H}_{2}: \mathrm{Ar}$ (flow ratio $2: 1$ ) at $V_{\mathrm{dc}}=450 \mathrm{~V}$ and $f=13.56 \mathrm{MHz}$. The IE was set at $30 \mathrm{eV}$ to avoid saturation.

ion and neutral counts are observed for $\mathrm{C}, \mathrm{CH}, \mathrm{C}_{2}$ and $\mathrm{C}_{2} \mathrm{H}$. Acetylene ions are the only species which shows a ratio $>1$.

The effect of varying plasma power and thus $V_{\mathrm{dc}}$ on neutral count rates is shown in figure 5. The initial pressure with no plasma $\left(V_{\mathrm{dc}}=0 \mathrm{~V}\right)$ was $8.6 \mathrm{mTorr}$; this dropped almost linearly with increasing bias to $6.2 \mathrm{mTorr}$ at $V_{\mathrm{dc}}=475 \mathrm{~V}$. The numbers in parenthesis after the species legends are the ratios of counts at a $V_{\mathrm{dc}}$ of $475 \mathrm{~V}$, normalized to that of argon. The bias value chosen represents optimum bias condition for film deposition.

The neutral species can be divided into three sets. Group I consists of the carbon atom and some carbon bearing radicals $\left(\mathrm{C}, \mathrm{C}_{2}, \mathrm{C}_{2} \mathrm{H}, \mathrm{C}_{2} \mathrm{H}_{3}\right.$ and $\mathrm{CH}$ ) which directly follow the exponential reduction of $\mathrm{C}_{2} \mathrm{H}_{2}$ with increasing $V_{\mathrm{dc}}$, figure $5(a)$. This reduction in count rate with bias is about 3 times greater than the drop in pressure noted above. In figure 5(b) group II comprises $\mathrm{Ar}, \mathrm{H}$ and $\mathrm{CH}_{3}$, which are almost bias independent. Group III (also figure 5(b)) consists of other molecules $\left(\mathrm{H}_{2} \mathrm{O}\right.$, $\left.\mathrm{CO}_{2}, \mathrm{C}_{4} \mathrm{H}_{2}\right)$ and radicals $\left(\mathrm{ArH}, \mathrm{OH} \mathrm{C}_{4} \mathrm{H}_{4}, \mathrm{C}_{2} \mathrm{H}_{4}\right)$ which display more complex behaviour with bias. For example, $\mathrm{C}_{4} \mathrm{H}_{2}$ 

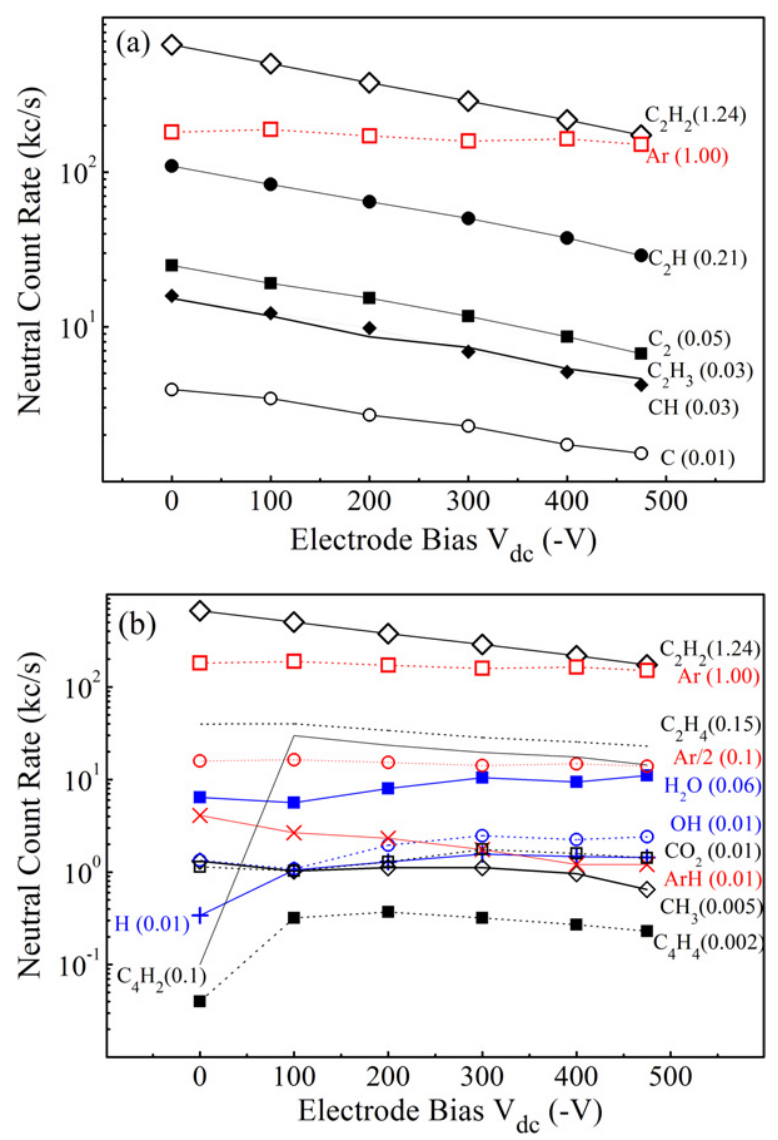

Figure 5. Neutral species variation with substrate bias in the CCP:

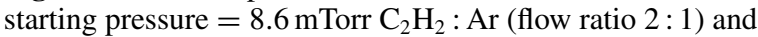
$f=13.56 \mathrm{MHz}$. The pressure dropped from $8.6 \mathrm{mTorr}$ at $V_{\mathrm{dc}}=0 \mathrm{~V}$ to $6.2 \mathrm{mTorr}$ at $V_{\mathrm{dc}}=475 \mathrm{~V}$. The ratios with respect to the argon value are shown in parentheses. (a) Species which reduce with $V_{\mathrm{dc}}$ (group I), (b) species which are almost constant with $V_{\mathrm{dc}}$ (group II) and species with more complex variation with $V_{\mathrm{dc}}$ (group III). For comparison, the argon and acetylene data are shown in both $(a)$ and (b). Note that the data shown for $V_{\mathrm{dc}}=0 \mathrm{~V}$ were recorded with the plasma off.

and $\mathrm{C}_{4} \mathrm{H}_{4}$ count rates increase significantly at plasma turn-on $\left(V_{\mathrm{dc}}>0 \mathrm{~V}\right)$. Further, in all groups, all observed species except $\mathrm{C}_{4} \mathrm{H}_{2}$ and $\mathrm{C}_{4} \mathrm{H}_{4}$ are present in significant quantities when the plasma is off $\left(V_{\mathrm{dc}}=0 \mathrm{~V}\right)$.

CCP IEDs, since they are measured at the grounded wall, cannot accurately represent the distributions at the driven electrode.

Figure 6(a) shows the ratio of count rates normalized to that of $\mathrm{C}_{2} \mathrm{H}_{2}$ at $V_{\mathrm{dc}}=475 \mathrm{~V}$ for group I members. The dominant $\mathrm{C}_{2} \mathrm{H}$ radical is an important precursor for a-C: $\mathrm{H}$ growth, (figure 6(a)). A similar plot for groups II and III, figure $6(b)$, shows the significant hydrocarbon species to be $\mathrm{C}_{2} \mathrm{H}_{4}$ and $\mathrm{C}_{4} \mathrm{H}_{2}$.

\subsection{ICP neutrals}

Figure 7 shows examples of the neutral count rates measured for both plasma-off and plasma-on for a range of pressures and electrode bias conditions. For all data the $\mathrm{C}_{2} \mathrm{H}_{2}$ : Ar flow ratio was $2: 1$ and ICP power was $200 \mathrm{~W}$. The upper scan limit was set at $70 \mathrm{amu}$ to maximize analyser operational lifetime.
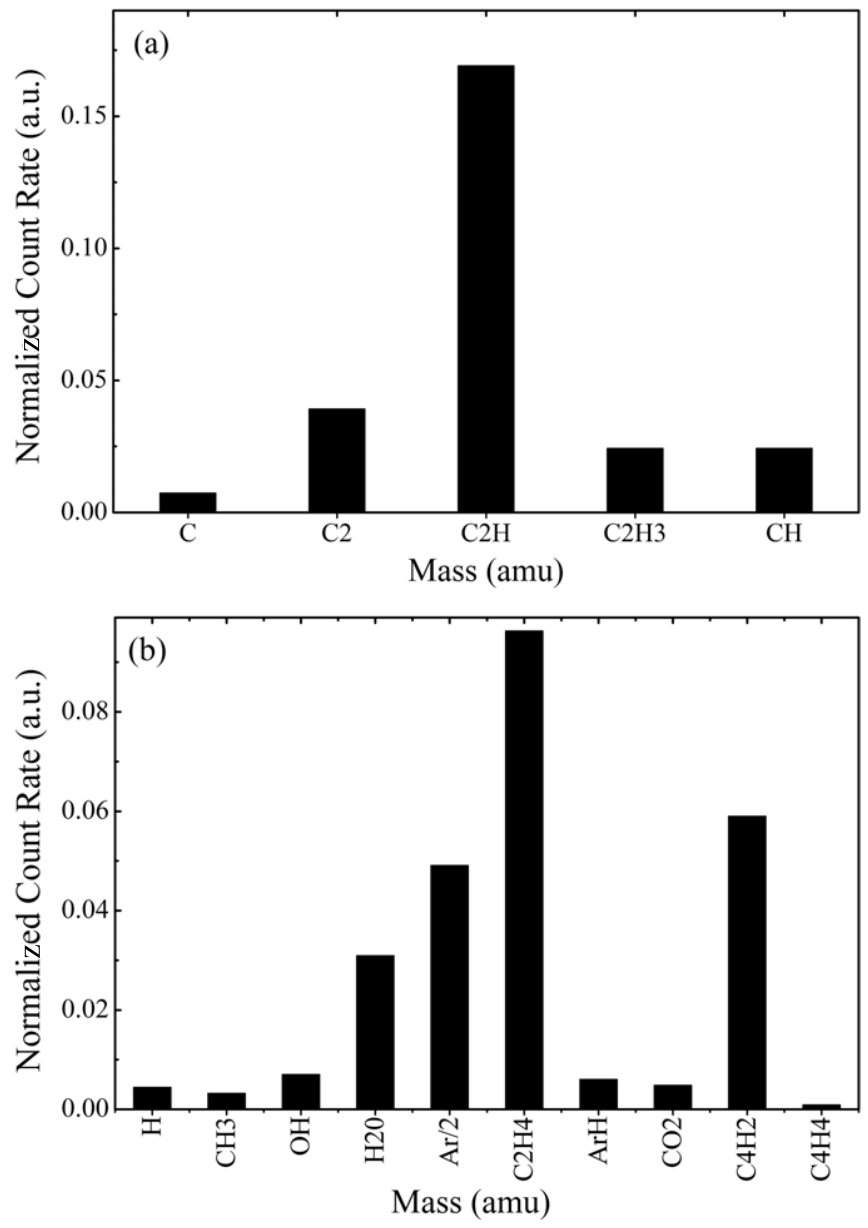

Figure 6. Neutral species normalized to $\mathrm{C}_{2} \mathrm{H}_{2}$ at $V_{\mathrm{dc}}=475 \mathrm{~V}$ in the

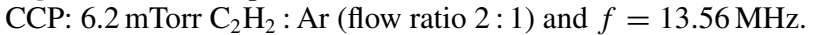
(a) Group I members. (b) Groups II and III.

All data were recorded under the same MEA measurement conditions, so count rates are directly comparable. Neutral count rates at a base pressure of $2 \times 10^{-6}$ Torr (plasma-off) show the nature and level of background impurities, namely water vapour $\mathrm{H}_{2} \mathrm{O}, \mathrm{N}_{2}$ and $\mathrm{C}_{2} \mathrm{H}_{6}$ (or $\mathrm{NO}$ ).

Plasma ignition resulted in changes in the species concentrations as well as the production of new species or destruction of old species before (white) and after plasma turnon (black). $\mathrm{H}_{3}, \mathrm{C}_{4}, \mathrm{C}_{4} \mathrm{H}_{2}, \mathrm{C}_{4} \mathrm{H}_{7}$ and $\mathrm{C}_{4} \mathrm{H}_{8}$ were observed only post-ignition at high bias frequency $(27 \mathrm{MHz}) . \mathrm{C}_{5} \mathrm{H}_{8}$ and $\mathrm{C}_{5} \mathrm{H}_{9}$ were the only new species observed at low bias frequency. New $\mathrm{H}_{n}$ species $(n=1-3)$ were observed, mainly at high pressure. Though the production of $\mathrm{H}_{3}$ is observed only at high bias frequency, its count rate at high pressure was 10 times greater than at low pressure. Significant reduction in $\mathrm{C}$ and $\mathrm{CH}$ concentrations were observed as pressure was raised from 3.3 to 25 mTorr. $\mathrm{C}_{2}$ is only observed in the plasma-off state. Argon neutral count remained constant while ArH variation was much more significant. Under all plasma conditions a significant decrease in $\mathrm{C}_{2} \mathrm{H}_{2}$ and $\mathrm{C}_{2} \mathrm{H}$ concentrations, the dominant carbon-carrying species, was observed compared with the plasma-off state.

The fall in pressure on plasma ignition and the loss of $\mathrm{C}_{2} \mathrm{H}_{2}$ were investigated in more detail by following the 


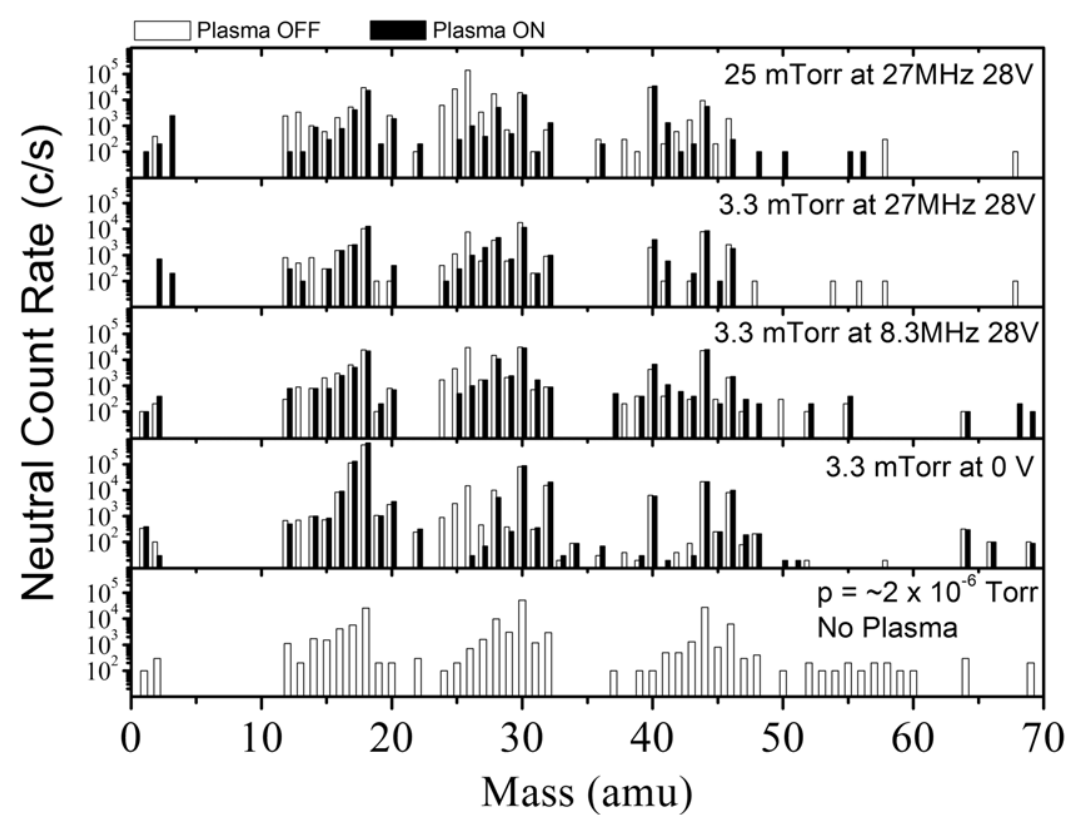

Figure 7. Neutral mass spectra in the ICP $\mathrm{C}_{2} \mathrm{H}_{2}$ : Ar (flow ratio $2: 1$ ) for various pressures, $V_{\text {bias }}$ and $f_{\text {bias. }}$. Data in black show plasma-on. Data in white show plasma-off. Also included is a mass spectrum at base pressure $\sim 2 \times 10^{-6}$ Torr.

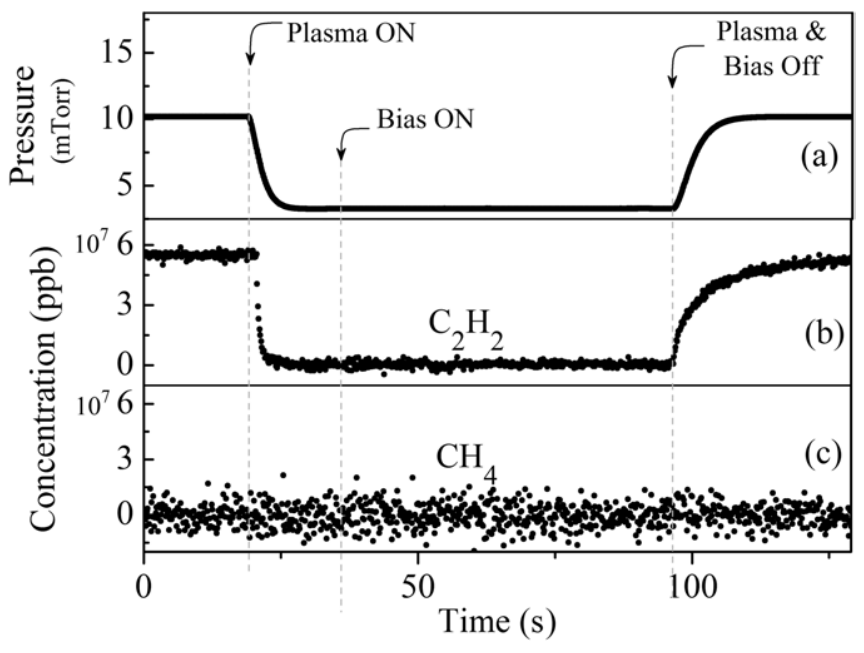

Figure 8. Chamber pressure and $\mathrm{C}_{2} \mathrm{H}_{2}$ and $\mathrm{CH}_{4}$ concentrations versus time in the ICP: 10 mTorr set pressure, $\mathrm{C}_{2} \mathrm{H}_{2}$ : Ar (flow ratio $2: 1)$. The plasma was turned on at $t=20 \mathrm{~s}$ and bias $(28 \mathrm{~V}$,

$8.311 \mathrm{MHz}$ ) at $35 \mathrm{~s}$. Both plasma and bias were turned off at $100 \mathrm{~s}$.

time evolution of the pressure and the IR absorption signal for $\mathrm{C}_{2} \mathrm{H}_{2}$ and $\mathrm{CH}_{4}$ species upon plasma switch-on, figure 8 (10 mTorr). The IR absorption measurements provide line integrated concentration values in the bulk plasma $110 \mathrm{~mm}$ above the substrate. At 10 mTorr, the $\mathrm{C}_{2} \mathrm{H}_{2}$ signal is seen to fall with an identical time constant $\tau$ to that of the pressure $(2.5 \mathrm{~s})$. The $\mathrm{CH}_{4}$ signal is barely visible above the background noise; however, at higher pressure, figure 9, its presence is significant. Here the $\mathrm{CH}_{4}$ is seen to rise rapidly $(<1 \mathrm{~s})$ upon plasma ignition and then fall with a similar time constant to that of pressure and $\mathrm{C}_{2} \mathrm{H}_{2}(\sim 20 \mathrm{~s})$, indicating $\mathrm{CH}_{4}$ as a transient by-product of $\mathrm{C}_{2} \mathrm{H}_{2}$ dissociation. It can be seen (figures 8 and 9) that bias has no effect on pressure or these species concentrations.

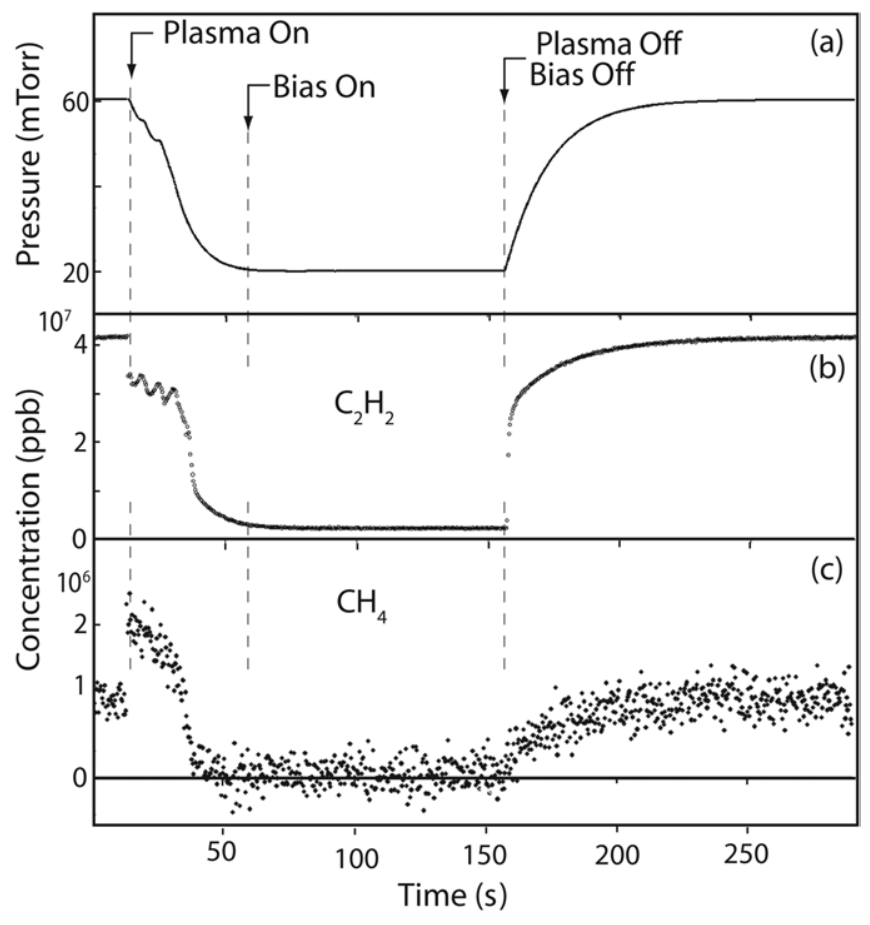

Figure 9. Chamber pressure and $\mathrm{C}_{2} \mathrm{H}_{2}$ and $\mathrm{CH}_{4}$ concentrations versus time in the ICP: 60 mTorr set pressure, $\mathrm{C}_{2} \mathrm{H}_{2}$ : Ar (flow ratio $2: 1)$. The plasma was turned on at $t \sim 15 \mathrm{~s}$ and bias $(28 \mathrm{~V}$,

$8.311 \mathrm{MHz}$ ) at $60 \mathrm{~s}$. Both plasma and bias were turned off at $\sim 160 \mathrm{~s}$.

In a separate experiment, a compensated Langmuir probe [35] $107 \mathrm{~mm}$ above the bias electrode was used to measure changes to bulk plasma parameters as acetylene was added to an argon discharge. Parameters were recorded every $5 \mathrm{~s}$ as a 3.3 mTorr $200 \mathrm{~W}$ Ar plasma was transformed by the introduction of $\mathrm{C}_{2} \mathrm{H}_{2}$ at $T \sim 40 \mathrm{~s}$. This addition of $16 \mathrm{sccm}$ $\mathrm{C}_{2} \mathrm{H}_{2}$, twice the Ar flow rate, caused the chamber pressure 


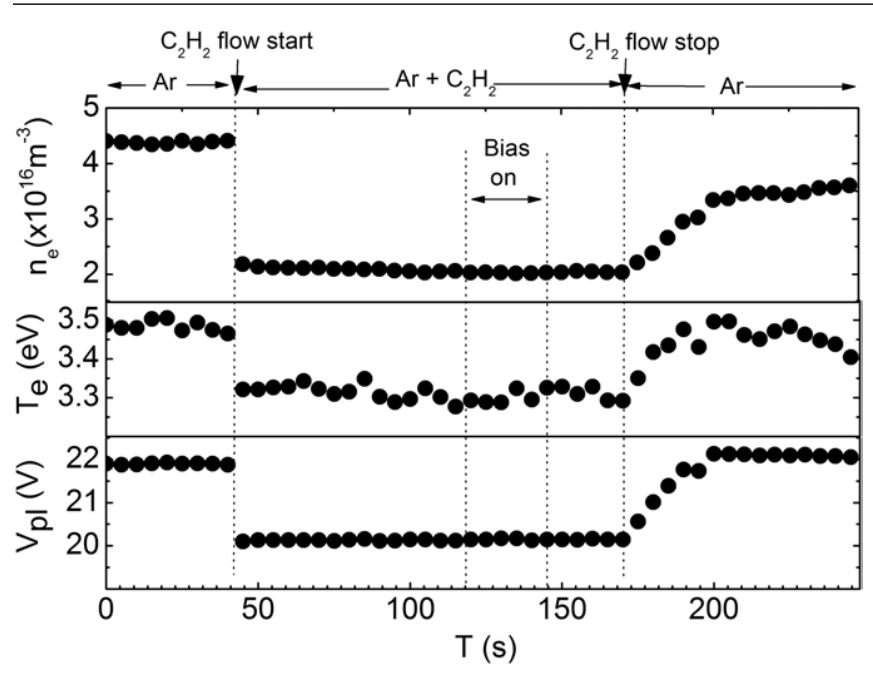

Figure 10. Plasma potential $\left(V_{\mathrm{pl}}\right)$, electron temperature $\left(T_{\mathrm{e}}\right)$ and electron density $\left(n_{\mathrm{e}}\right)$ versus time in the ICP. The $200 \mathrm{~W}$ plasma was ignited in pure argon (3.3 mTorr) at $T<0 \mathrm{~s}$ and $\mathrm{C}_{2} \mathrm{H}_{2}$ was added at $T=40 \mathrm{~s}$ (with $\mathrm{a} \mathrm{C}_{2} \mathrm{H}_{2}:$ Ar flow ratio of $2: 1$ ). Bias $(28 \mathrm{~V}$,

$8.311 \mathrm{MHz}$ ) was applied for $120 \mathrm{~s}<T<145 \mathrm{~s}$. The $\mathrm{C}_{2} \mathrm{H}_{2}$ flow was turned off at $T \sim 170 \mathrm{~s}$.

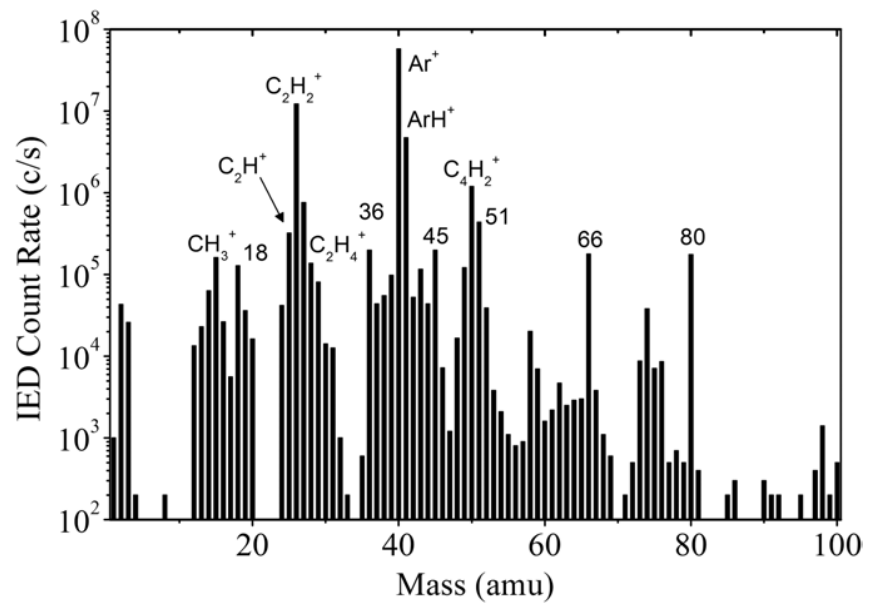

Figure 11. IM spectrum in the ICP: $4.5 \mathrm{mTorr}_{2} \mathrm{H}_{2}$ : Ar (flow ratio $1: 20), 40 \mathrm{~W} 13.56 \mathrm{MHz}$ and electrode grounded.

to rise to 4.1 mTorr. The $\mathrm{C}_{2} \mathrm{H}_{2}$ flow was turned off at $T \sim$ $170 \mathrm{~s}$. The addition of acetylene to the plasma volume led to significant changes in the plasma, figure 10 . The values of $V_{\mathrm{pl}}, T_{\mathrm{e}}$ and $n_{\mathrm{e}}$ dropped within $5 \mathrm{~s} \mathrm{(cf} \tau \sim<2.5 \mathrm{~s}$, figure 8 ) to near constant levels: $n_{\mathrm{e}}$ by a factor of $2, T_{\mathrm{e}}$ by $\sim 5 \%$ and $V_{\mathrm{pl}}$ from 22 to $20 \mathrm{~V}$. For a short period $(120 \mathrm{~s}<T<145 \mathrm{~s})$ the sample electrode bias was turned on so that $V_{\text {bias }}=100 \mathrm{~V}$; no significant changes were observed. $V_{\mathrm{pl}}$ and $T_{\mathrm{e}}$ were restored to their original values within $30 \mathrm{~s}$ of $\mathrm{C}_{2} \mathrm{H}_{2}$ turn off, whereas the $n_{\mathrm{e}}$ recovery was slower. Note that for this study, $T_{\mathrm{e}}$ was determined simply from the slope of the compensated Langmuir probe IV characteristic.

\subsection{ICP positive ions}

Figure 11 shows positive ionic species up to mass $100 \mathrm{amu}$ for a $40 \mathrm{~W}$ E-mode ICP discharge with a $\mathrm{C}_{2} \mathrm{H}_{2}$ : Ar gas flow ratio of $1: 20$ and pressure of $4.5 \mathrm{mTorr}$. Ions from the two

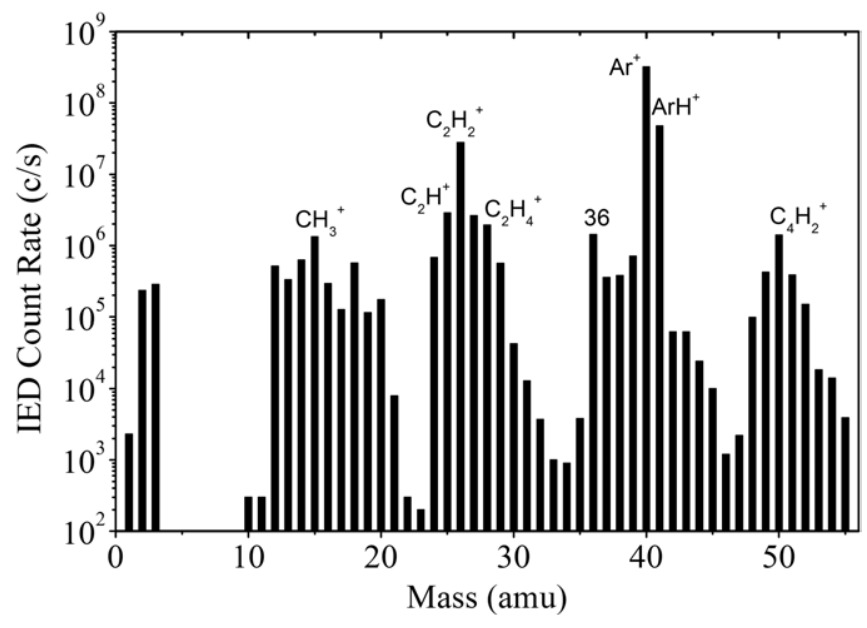

Figure 12. IM spectrum in the ICP: $3.3 \mathrm{mTorr}_{2} \mathrm{C}_{2}$ : $\mathrm{Ar}$ (flow ratio $2: 1), 200 \mathrm{~W} 13.56 \mathrm{MHz}$ and substrate bias $7 \mathrm{~V}$ at $8.311 \mathrm{MHz}$.

feed gases $\mathrm{Ar}^{+}$and $\mathrm{C}_{2} \mathrm{H}_{2}^{+}$dominate, and with $\mathrm{ArH}^{+}$and $\mathrm{C}_{4} \mathrm{H}_{2}^{+}$, make up $95 \%$ of the total count. The majority of species with count rates greater than $10^{3}$ times that of $\mathrm{Ar}^{+}$are identified as hydrocarbons, and may be grouped into families based on carbon content:

$$
\begin{aligned}
& \mathrm{CH}_{3}^{+} \\
& \mathrm{C}_{2} \mathrm{H}_{2}^{+}, \mathrm{C}_{2} \mathrm{H}_{3}^{+}, \mathrm{C}_{2} \mathrm{H}_{4}^{+}, \mathrm{C}_{2} \mathrm{H}_{5}^{+} \\
& \mathrm{C}_{3} \mathrm{H}_{3}^{+}, \mathrm{C}_{3} \mathrm{H}_{5}^{+}, \mathrm{C}_{3} \mathrm{H}_{7}^{+} \\
& \mathrm{C}_{4} \mathrm{H}^{+}, \mathrm{C}_{4} \mathrm{H}_{2}^{+}, \mathrm{C}_{4} \mathrm{H}_{3}^{+} \\
& \mathrm{C}_{5} \mathrm{H}_{6}^{+} \\
& \mathrm{C}_{6} \mathrm{H}_{8}^{+} .
\end{aligned}
$$

Water and argon isotopes with their associated hydrides make up the remainder.

Similar data for the higher power $\mathrm{H}$-mode ICP discharge are shown in figure 12 for a $200 \mathrm{~W}$ plasma with $\mathrm{C}_{2} \mathrm{H}_{2}$ : Ar gas flow ratio of $2: 1$ and pressure of 3.3 mTorr. By comparison with the low power ICP case, $\mathrm{Ar}^{+}, \mathrm{ArH}^{+}$and $\mathrm{C}_{2} \mathrm{H}_{2}^{+}$contribute, in order of dominance, $95 \%$ of the total count. The remainder (to $99.5 \%$ ) consists of $\mathrm{CH}_{3}^{+}, \mathrm{C}_{2} \mathrm{H}^{+}, \mathrm{C}_{2} \mathrm{H}_{3}^{+}, \mathrm{C}_{2} \mathrm{H}_{4}^{+}$, mass 36 $\left(\mathrm{C}_{3}^{+}\right.$and $\left.{ }^{36} \mathrm{Ar}^{+}\right), \mathrm{C}_{4} \mathrm{H}_{2}^{+}$.

The count rates of the dominant ions $\left(\mathrm{Ar}^{+}, \mathrm{ArH}^{+}, \mathrm{C}_{2} \mathrm{H}_{2}^{+}\right)$ plus those of possible importance in DLC growth $\left(\mathrm{CH}_{3}^{+}, \mathrm{C}_{2} \mathrm{H}^{+}\right.$, $\mathrm{C}_{2} \mathrm{H}_{4}^{+}, \mathrm{C}_{4} \mathrm{H}_{2}^{+}$) were measured for various pressure, bias voltage and bias frequency conditions in ICP H-mode $(200 \mathrm{~W})$ with a gas mixture $\mathrm{C}_{2} \mathrm{H}_{2}$ : Ar flow ratio of $2: 1$, figure 13 . The species count rates generally retain their order of abundance across the whole data set. $\mathrm{Ar}^{+}$or $\mathrm{ArH}^{+}$are either first or second, followed by $\mathrm{C}_{2} \mathrm{H}_{2}^{+}$and then $\mathrm{C}_{2} \mathrm{H}^{+}, \mathrm{C}_{4} \mathrm{H}_{2}^{+}$or $\mathrm{CH}_{3}^{+}$are either fifth or sixth and $\mathrm{C}_{2} \mathrm{H}_{4}^{+}$usually has the lowest count rate. Measured count rates do, however, vary with pressure, bias voltage and frequency. Figures $13(c)$ and $(d)$ show ion count rates for the above species at $8.311 \mathrm{MHz}$ bias. The flux decreases consistently as bias is increased from 7 to $100 \mathrm{~V}$ at 3.3 mTorr, whereas the opposite behaviour is observed for the two biases recorded at 20 mTorr. At $27 \mathrm{MHz}$ bias (figures 13(a) and $(b))$, the flux minimizes at $52 \mathrm{~V}$ bias at 3.3 mTorr, whereas it decreases with increasing bias at 25 mTorr.

Figure 14 shows ion count rates measured at high pressure. $\mathrm{A} \mathrm{C}_{2} \mathrm{H}_{2}$ : Ar flow ratio of $2: 1$ was found not to be reproducibly stable and therefore a flow ratio of $1: 20$ was used. Positive 


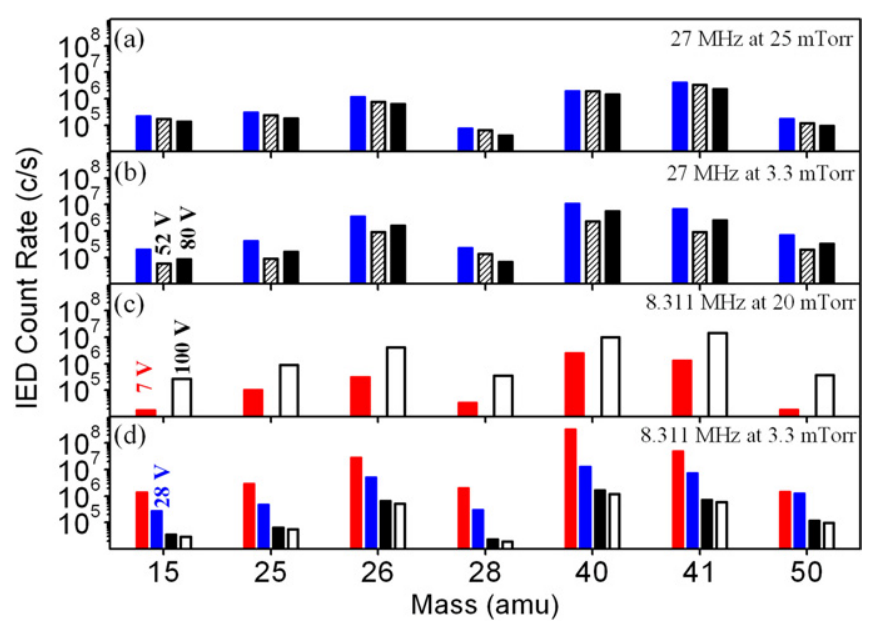

Figure 13. Dominant ionic species $\left(\mathrm{CH}_{3}^{+}, \mathrm{C}_{2} \mathrm{H}^{+}, \mathrm{C}_{2} \mathrm{H}_{2}^{+}, \mathrm{C}_{2} \mathrm{H}_{4}^{+}, \mathrm{Ar}^{+}\right.$, $\mathrm{ArH}^{+}, \mathrm{C}_{4} \mathrm{H}_{2}^{+}$) in the ICP: $\mathrm{C}_{2} \mathrm{H}_{2}$ : $\mathrm{Ar}$ (flow ratio $2: 1$ ), $200 \mathrm{~W}$ $13.56 \mathrm{MHz}$ for various pressures, $V_{\text {bias }}$ and $f_{\text {bias. }}$.

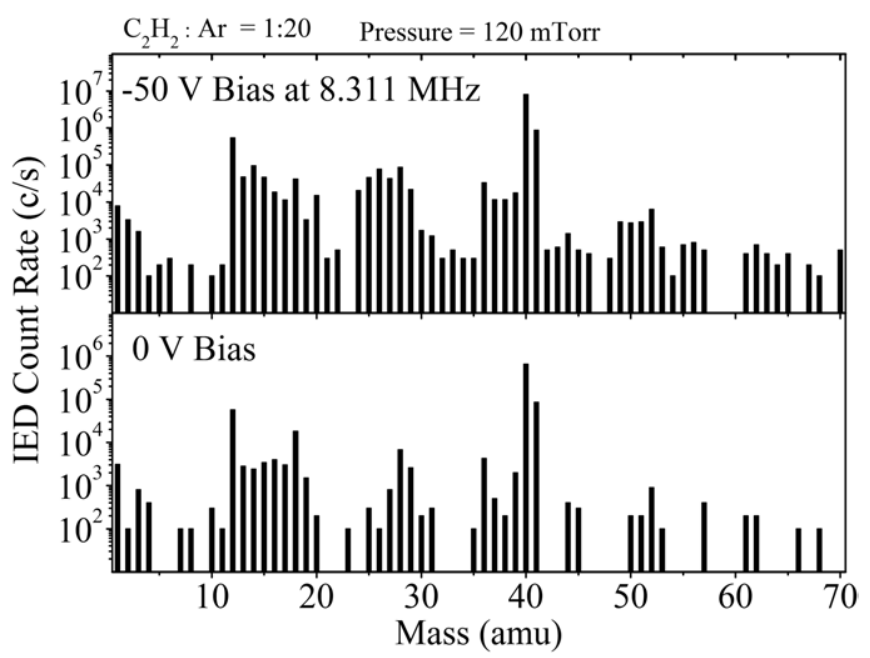

Figure 14. IM spectrum in the ICP: $120 \mathrm{mTorr}_{2} \mathrm{H}_{2}$ : $\mathrm{Ar}$ (flow ratio $1: 20), 200 \mathrm{~W} 13.56 \mathrm{MHz}$ for $V_{\text {bias }}=0 \mathrm{~V}$ (electrode grounded) and $V_{\text {bias }}=50 \mathrm{~V}$ bias and $f_{\text {bias }}=8.311 \mathrm{MHz}$.

ionic species count up to mass $70 \mathrm{amu}$ was measured at $200 \mathrm{~W}$ ICP power for both biased $\left(8.311 \mathrm{MHz}, V_{\text {bias }}=50 \mathrm{~V}\right)$ and grounded electrode conditions. Ions $\mathrm{Ar}^{+}, \mathrm{ArH}^{+}$and $\mathrm{C}^{+}$contributed $\sim 92 \%$ of the total ions irrespective of the substrate bias. $\mathrm{C}_{2} \mathrm{H}_{2}^{+}$, which appears to be the dominant ion at $\mathrm{C}_{2} \mathrm{H}_{2}$ : Ar flow ratio of $2: 1$, was found to contribute almost nil at grounded electrode whereas $\sim 1 \%$ was observed at $50 \mathrm{~V}$ substrate bias. Other positive ions which were only produced at high substrate bias were $\mathrm{C}_{2} \mathrm{H}^{+}, \mathrm{C}_{2} \mathrm{H}_{5}^{+}, \mathrm{C}_{2}^{+}, \mathrm{Ar}^{++}, \mathrm{C}_{3} \mathrm{H}^{+}$, $\mathrm{C}_{3} \mathrm{H}_{2}^{+}$. In addition $\mathrm{CH}_{2}^{+}, \mathrm{CH}^{+}, \mathrm{CH}_{3}^{+}, \mathrm{H}_{2} \mathrm{O}^{+}, \mathrm{C}_{3}^{+}, \mathrm{CH}_{4}^{+}, \mathrm{C}_{2} \mathrm{H}_{3}^{+}$, $\mathrm{C}_{3} \mathrm{H}_{3}^{+}$were observed at both low and high biases whereas $\mathrm{H}^{+}$ and $\mathrm{C}_{4} \mathrm{H}_{4}^{+}$were observed only at $0 \mathrm{~V}$ bias.

\section{Discussion}

The low pressure acetylene-argon plasma is an important and widely used process in materials deposition but detailed plasma characterization is lacking, not least because of the challenges of diagnostics in high rate deposition environments.
The neutral and positive ionic species measured here in low pressure (3-120 mTorr) CCP and ICP systems are the first such measurements published with $\mathrm{C}_{2} \mathrm{H}_{2}$ : Ar as the working gas. It should be noted that $\mathrm{C}_{x} \mathrm{H}_{y}$-based plasmas offer a wide range of complex reaction paths $[9,23,27,36-38]$. This is further complicated by adding argon, so accurate determination of $\mathrm{C}_{2} \mathrm{H}_{2}$ : Ar reaction probabilities requires additional detailed modelling.

In this paper we suggest mechanisms to explain some of the observations; the task is, however, too complex to account for them all. In particular, the most important growth precursor for DLC is the $\mathrm{C}_{2} \mathrm{H}$ radical [22]. Accurate measurement of this radical is particularly challenging and hence it is worth considering possible $\mathrm{C}_{2} \mathrm{H}_{2}$ to $\mathrm{C}_{2} \mathrm{H}$ conversion mechanisms. Also of interest is the impact on growth models when the presumed dominance of $\mathrm{C}_{2} \mathrm{H}_{2}^{+}$is replaced by $\mathrm{Ar}^{+}$or $\mathrm{ArH}^{+}$, hence affecting the direct carbon ion subplantation rates. Measured species represent fluxes at the measurement point derived from species originating within the bulk plasma, through homogeneous processes, and also due to heterogeneous reactions, i.e. species released from the walls, electrodes and even particulates. Although the variation of the plasma density, across all species, cannot be accurately determined, it is nevertheless, the actual flux at the substrate that determines growth reactions. The significance and nature of wall-released species is difficult to determine and is the focus of modelling and specific experimental effort elsewhere [21, 37, 39, 40].

Heterogeneous reactions, occurring at the grounded chamber wall or at the biased electrode, represent potential surface loss mechanisms for plasma generated species as well as a potential source for new radicals. The reactivity of such surfaces is particularly sensitive to ion-bombardment conditions, the nature and structure of impinging radicals and the flux of hydrogen (atoms and ions). Bombarding ions, greater than a few $\mathrm{eV}$ and below the classical sputter threshold energies, cause surface bond breaking and hydrogen displacement within the hydrogenated carbon wall/electrode coating. At the coating surface this results in the generation of dangling bonds which act as chemisorption sites for many of the $\mathrm{C}_{x} \mathrm{H}_{y}$ radicals. This is particularly so for hydrogen ions where most of their kinetic energy is consumed in bonded hydrogen displacement [42]. At high ion fluxes, dangling bond sites overlap leading to saturation in their density [40]. Carbon-carrying ions, in addition to dangling bond formation, also contribute to film deposition due to an effective sticking coefficient of $\sim 1$ [17] or at sufficiently high energies may cause sputtering (along with inert ions). In the context of this paper, the neutral species-surface reactions can be categorized as reflection, sticking (directly or through intermediate surface reactions) or surface transformation to another volatile species which either sticks or desorbs into the plasma. Sticking coefficients depend on the nature of the particular radical and are often enhanced in the presence of ion bombardment since the radical to dangling bond coefficients are $\sim 1$ [64]. When a carbon atom sticks to the surface, its available valence electrons allow the formation of one to three subsequent bonds. Diradicals can bond directly with $\mathrm{C}-\mathrm{C}$ or 
$\mathrm{C}-\mathrm{H}$ surfaces and their sticking coefficient is $\sim 1$. However, larger species $\left(\mathrm{C}_{x} \mathrm{H}_{y}, x>2\right)$ have only one valence electron to bind to the surface and hence need a dangling bond to stick. Also, subsequent incoming particles cannot simply chemisorb onto these molecules. Closed-shell neutrals have sticking coefficients of almost zero [65]. Unsaturated hydrocarbon radicals (e.g. $\mathrm{C}_{2} \mathrm{H}$ or $\mathrm{C}_{2} \mathrm{H}_{3}$ ) have a sticking coefficient of $\sim 1$ and their chemisorption only weakly depends on any surface activation [42] and for $\mathrm{C}_{2} \mathrm{H}$, new dangling bonds can be created on adsorption, if the hybridization changes [17]. For small $\mathrm{C}_{x} \mathrm{H}$ radicals, one carbon atom is shielded by the hydrogen and rarely sticks hence their reactivity may be expected to be lower than the equivalent $\mathrm{C}_{x}$ radical where two atoms can stick [66]. Cyclic radicals, e.g. $\mathrm{C}_{3}$ and $\mathrm{C}_{3} \mathrm{H}$, are structurally unstable and also each atom has an available electron for surface binding so that a high sticking coefficient can be expected [66]. The flux of hydrogen species is also important. Atomic hydrogen can create chemisorption sites (dangling bonds) by the abstraction of surface bonded $\mathrm{H}$ to form $\mathrm{H}_{2}$, which desorbs into the plasma, or it can adsorb and passivate dangling bonds in a competing process. Successive ion-induced bond breaking and $\mathrm{H}$-atom passivation within the surface layer can lead to chemical erosion via the formation of weakly bonded $\mathrm{C}_{x} \mathrm{H}_{y}$ species which can diffuse to the surface and desorb $[67,40]$. In our ICP system, the spectrometer orifice and vicinity are subjected to ion bombardment with a higher energy and flux compared with the CCP case, where the EQP is positioned at the grounded wall. Thus the sticking efficiency of radicals and the ion/H-atom induced volatile production are likely to differ significantly.

Radicals with a low $\mathrm{H}$ number, e.g. $\mathrm{C}_{2} \mathrm{H}$, are mainly formed in $\mathrm{C}_{2} \mathrm{H}_{2}$-based plasmas and often such highly reactive radicals have a gas-phase lifetime much shorter than the diffusion time to chamber walls [68] and estimates of species lifetimes and diffusion rates for our ICP are in agreement. These gas-phase reactions may involve polymerization reactions, particularly the addition of $\mathrm{C}_{2} \mathrm{H}$ to the parent molecule, leading to long-chained poly-acetylene molecules. Negative ions are also formed in these plasmas, mainly through dissociative electron attachment, and with successive anion- $\mathrm{C}_{2} \mathrm{H}_{2}$ reactions, gas-phase nanoparticles can grow. Subsequent heterogeneous interactions between radicals and such gas-phase surfaces may be the source of additional volatiles, later detected at the spectrometer. The direct flux of nanoparticles to the spectrometer orifice (and subsequent fragmentation) is only possible for (i) positively charged particles which therefore must have very small diameters or for (ii) very large diameter particles where the force of gravity overcomes the sheath field. In the ICP system, the introduction of $\mathrm{C}_{2} \mathrm{H}_{2}$ into an argon plasma resulted in a reduction in electron density by a factor of $>2$ and a slight fall in electron temperature, figure 10 . The former, along with $\mathrm{C}_{2} \mathrm{H}_{2}$ molecule consumption, figure 8 , could be indicative of negative ion formation and particle growth. The concentration of $\mathrm{C}_{2} \mathrm{H}^{-}$anion species is considered a crucial parameter for the initiation of particle growth [70]. The ICP production rate for $\mathrm{C}_{2} \mathrm{H}^{-}$via electron dissociation is estimated to be $1 \times$ $10^{16} \mathrm{~m}^{-3} \mathrm{~s}^{-1}$, four orders lower than the $\mathrm{Ar}^{+}$direct ionization rate. Negative ion density is enhanced by trapping within the plasma but estimation of lifetimes is particularly complex. Other important factors related to particle formation in $\mathrm{C}_{2} \mathrm{H}_{2}$ plasmas include an associated increase in electron temperature, which is not observed in our case, and the concentration of source acetylene species [69]. Particle generation has been reported at higher pressures ( $>75$ mTorr) than used here $[69,20]$. It is therefore unlikely that significant generation of particles is occurring under our ICP experimental conditions despite the presence of a small number $\left(<0.1 \%\right.$ of $\mathrm{Ar}^{+}$count $)$ of high mass $(>70)$ positive ionic species, figure 11 .

The $\mathrm{C}_{2} \mathrm{H}_{2}$ partial pressure drop at plasma turn-on for mixtures, typically from 6.7 mTorr to $<0.3$ mTorr in the ICP, was noted in section 3 , and is associated with a dramatic loss of the $\mathrm{C}_{2} \mathrm{H}_{2}$, as evidenced by IR absorption $v$ time, figures 8 and 9. The typical argon partial pressure 3.3 mTorr remained unaffected. Thus, the dominance of both Ar neutrals and ions, despite the input gas flow ratio, is unsurprising. In the CCP, it was observed that loss of $\mathrm{C}_{2} \mathrm{H}_{2}$ was dependent on the input power, figure 5 . For powers up to $130 \mathrm{~W}\left(V_{\mathrm{dc}}=475 \mathrm{~V}\right)$ $\mathrm{C}_{2} \mathrm{H}_{2}^{+}$remains the dominant ion, an indication of the lower dissociation in the CCP versus the ICP, given the lower power coupling efficiency of the former. One potential mechanism for $\mathrm{C}_{2} \mathrm{H}_{2}$ reduction is the hydrogen abstraction from acetylene by electron dissociation $[38,41]$ equations (1) and (2):

$$
\begin{gathered}
\mathrm{C}_{2} \mathrm{H}_{2}+\mathrm{e} \rightarrow \mathrm{C}_{2} \mathrm{H}+\mathrm{H}+\mathrm{e} \\
\mathrm{C}_{2} \mathrm{H}_{2}+\mathrm{e} \rightarrow \text { all. }
\end{gathered}
$$

The sum of the calculated ICP rates for these reactions is $6.6 \times 10^{19} \mathrm{~m}^{-3} \mathrm{~s}^{-1}$ (table 2, section 4.5), almost equal to the ICP $\mathrm{C}_{2} \mathrm{H}_{2}$ flow rate of $16 \mathrm{sccm}\left(\sim 1 \times 10^{19}\right.$ molecules s $^{-1}$ into the $95 \mathrm{~L}$ chamber, i.e. $\left.\sim 7.5 \times 10^{19} \mathrm{~m}^{-3} \mathrm{~s}^{-1}\right)$.

Due to the high surface loss probability $(\beta \sim 0.9)$ of the $\mathrm{C}_{2} \mathrm{H}$ radical [42], the $\mathrm{C}_{2} \mathrm{H}$ produced via equation (1) readily sticks to chamber wall surfaces and hence is lost from the volume. This conversion of neutral $\mathrm{C}_{2} \mathrm{H}_{2}$ combined with high surface loss probability of the $\mathrm{C}_{2} \mathrm{H}$ radical may explain the initial drop in pressure. In effect the chamber walls are acting as an additional pumping source. To our knowledge there are no other reports of this pressure phenomenon in studies of $\mathrm{C}_{2} \mathrm{H}_{2}$ with argon dilution at low pressure, although a similar effect has recently been observed in a gas mixture of $\mathrm{Ar}: \mathrm{He}: \mathrm{C}_{2} \mathrm{H}_{2}(4: 15: 4)$ at 45 mTorr [71]. Our pressure control systems are operated in free-running mode where the total flow and flow ratio rather than pressure is set. Again this is standard practice. Nevertheless, those systems operated in automatic constant pressure mode should respond with considerable increases in flow and hence much greater deposition throughout. For pure $\mathrm{C}_{2} \mathrm{H}_{2}$ studies, Vasile and Smolinsky [23] report severe experimental difficulties with pure $\mathrm{C}_{2} \mathrm{H}_{2}$ due to rapid deposition of polymer-like material which blocks the spectrometer orifice and they needed to dilute the acetylene with rare gases.

Our suggested mechanism of $\mathrm{C}_{2} \mathrm{H}_{2}$ loss, equation (1), requires a decisive conversion to $\mathrm{C}_{2} \mathrm{H}$ that is not, however, detected by the MEA. This may be due to the transmission function of the MEA orifice, which has an aspect ratio 
(height/diameter) of $\sim 10$. Thus, only $\mathrm{C}_{2} \mathrm{H}$ molecules that arrive almost on-axis (within a solid angle of $0.04 \mathrm{sr}$ ) will traverse the orifice without interaction with the wall. Due to the high sticking coefficient, most $\mathrm{C}_{2} \mathrm{H}$ molecules with higher angles of incidence will stick to the wall, whereas all $\mathrm{C}_{2} \mathrm{H}_{2}$ molecules will be transmitted, even if wall contact is made. Thus the orifice, due to its geometry, can be expected to function as a blocking filter for $\mathrm{C}_{2} \mathrm{H}$. An estimate of the relative $\mathrm{C}_{2} \mathrm{H} / \mathrm{C}_{2} \mathrm{H}_{2}$ transmission probability is $7 \%$. Note that in order to prevent build-up of deposit on the orifice wall, thus reducing the transmission further, we undertake an $\mathrm{Ar} / \mathrm{O}_{2}$ plasma clean between each run. Without this step we can observe total orifice closure with deposited material.

Another factor that needs consideration is the transient production of $\mathrm{CH}_{4}$ during the pressure drop at plasma turnon, figure 9, as determined by IR absorption. At 10 mTorr the overall $\mathrm{CH}_{4}$ concentration is below our detection level (in the presence of $\mathrm{C}_{2} \mathrm{H}_{2}$ ). However, at higher pressure we note an immediate rise in $\mathrm{CH}_{4}$ to $3.6 \%$ of the set $\mathrm{C}_{2} \mathrm{H}_{2}$ concentration, followed by a similar decay to that of pressure and $\mathrm{C}_{2} \mathrm{H}_{2}$, implying a direct $\mathrm{C}_{2} \mathrm{H}_{2}-\mathrm{CH}_{4}$ relationship. Note that the transient evolution of species cannot be detected by the MEA since the measurement (and software synchronization) time is approximately $3 \mathrm{~s}$. Serdioutchenko et al [43] have also observed transient effects in a $\mathrm{CH}_{4}-\mathrm{Ar}$ plasma with $\mathrm{CH}_{4}$ conversion to $\mathrm{C}_{2} \mathrm{H}_{2}$ and higher hydrocarbons. However, the 'reverse' conversion of $\mathrm{C}_{2} \mathrm{H}_{2}$ to $\mathrm{CH}_{4}$ has not been observed and is not considered probable in the $\mathrm{C}_{2} \mathrm{H}_{2}$ literature. This is possibly due to the lack of time-resolved measurements of $\mathrm{C}_{2} \mathrm{H}_{2}$ plasmas to date. In high pressure diamond plasma chemistry, the very high $\mathrm{H}$-atom densities promote $\mathrm{H}$ addition reactions that convert $\mathrm{C}_{2} \mathrm{H}_{2}$ to $\mathrm{CH}_{x}(x=1,2,3,4)$ in the cooler regions [72]. Here $\mathrm{C}_{2} \mathrm{H}_{2}$ molecules in the presence of $\mathrm{H}$ atoms are transformed to other hydrocarbons $\left(\mathrm{C}_{2} \mathrm{H}_{2+n} n=1,2,3\right)$, before converting to $\mathrm{CH}_{3}$ then $\mathrm{CH}_{x}(x=1,2,3,4)$ with most reactions involving a third body [73].

Rates of evolution of $\mathrm{CH}_{4}$ from $\mathrm{H}$-atom exposed graphite have been observed [74] and the mechanism is considered to be based on $\mathrm{H}$-atom impingement at surface sites with an associated pair of chemisorbed hydrogen atoms, to form a $\mathrm{CH}_{3}$ group. This group is then converted to volatile $\mathrm{CH}_{4}$ by the rapid addition of another $\mathrm{H}$-atom. Competing reactions include $\mathrm{H}_{2}$ formation/desorption as well as a $\mathrm{CH}_{3}$ group reaction with an adjacent group to form a stable adsorbed species which blocks further production at that site. Thus $\mathrm{CH}_{4}$ evolution peaks rapidly on $\mathrm{H}$-exposure and then decays over tens of seconds to an equilibrium value. Upper limits for $\mathrm{H}$-atom/graphite sticking coefficients are $<0.04$ and the production efficiency is $<10^{-3} \mathrm{CH}_{4} / \mathrm{H}$. In our case, $\mathrm{CH}_{4}$ concentrations follow the temporal behaviour of the acetylene (at 27 mTorr) at around 5-10\% of the $\mathrm{C}_{2} \mathrm{H}_{2}$ concentration, during the initial decay (over $\sim 40 \mathrm{~s}$ ). To obtain similar $\mathrm{CH}_{4}$ evolution efficiency as in [74] requires a much higher $\mathrm{H}$-atom flux than is possible from our observed hydrogen species densities. We estimate a $\mathrm{C}_{2} \mathrm{H}$ flux of $3 \times 10^{17} \mathrm{~m}^{-2} \mathrm{~s}^{-1}$ from the MEA measured species assuming a neutral species temperature of $500 \mathrm{~K}$. Assuming a $\mathrm{H}$-atom flux similar to the $\mathrm{C}_{2} \mathrm{H}$ flux, from equation (1), results in an estimated $\mathrm{CH}_{4}$ rise time of $>10^{3} \mathrm{~s}$, compared with our measured value of $\sim 100 \mathrm{~ms}$. However, surface conditions in our setup may lead to considerably higher $\mathrm{H}$-atom sticking coefficients due to ion-bombardment induced dangling bonds. These dangling bonds normally also act as preferential sites for $\mathrm{C}$-species adsorption, e.g. $\mathrm{CH}_{3}$, where tri-hydride surface groups are formed and then transformed by incoming hydrogen to radical $\mathrm{CH}_{2}$ groups via $\mathrm{H}$-elimination reactions $[67,42]$. These in turn recombine with neighbours to form the crosslinked carbon-hydrogen film network. Hydrogen elimination becomes increasingly more difficult if a fully constrained network is approached leading to a stoichiometric limit of surface $\mathrm{H} / \mathrm{C} \sim 1$. However, even a best case $\mathrm{H}$-atom sticking coefficient of one leads to a $\sim 10 \mathrm{~s}$ rise time. If we also add the maximum possible $\mathrm{C}_{2} \mathrm{H}$ flux (i.e. assuming no loss in the plasma) as a further source of the necessary precursor sites to $\mathrm{CH}_{4}$ generation, then the estimated rise time is still too long by a factor of 30. Benedikt et al [68], using time-resolved RGA, report that on addition of $10 \% \mathrm{H}_{2}$ to an $\mathrm{Ar}$ plasma, $\mathrm{CH}_{4}$ is liberated from an a-C : $\mathrm{H}$ surface in such quantities as to raise the $\mathrm{CH}_{4}$ partial pressure to $\sim 1 / 70$ of the hydrogen. However, the temporal resolution in this experiment was about $10 \mathrm{~s}$ and hence direct comparison is not possible.

In the plasma-off state, apart from input gases and impurity species, we have also observed other species such as $\mathrm{C}_{2} \mathrm{H}$ and $\mathrm{CH}_{3}$. These may be indicators of derivative species generation within the MEA (in the NM mode) due to electron dissociative ionization of $\mathrm{C}_{2} \mathrm{H}_{2}$ in the ionization source. The filament electron energy is normally set to $70 \mathrm{eV}$, about $5-15 \mathrm{eV}$ above the energy at which maximum total ionization cross-section occurs [45]. As an example, we consider two reaction pathways within the MEA, namely

$$
\begin{aligned}
& \mathrm{e} \text { (filament) }+\mathrm{C}_{2} \mathrm{H}_{2} \rightarrow \mathrm{C}_{2} \mathrm{H}_{2}^{+}+2 \mathrm{e} \\
& \mathrm{e} \text { (filament) }+\mathrm{C}_{2} \mathrm{H} \rightarrow \mathrm{C}_{2} \mathrm{H}^{+}+2 \mathrm{e} .
\end{aligned}
$$

The first reaction, equation (3), will add to the $\mathrm{C}_{2} \mathrm{H}_{2}$ counts at the MEA detector, while the second, equation (4), will add erroneous counts for the $\mathrm{C}_{2} \mathrm{H}$ radical and underestimate the $\mathrm{C}_{2} \mathrm{H}_{2}$ count. The measured ratio of $\mathrm{C}_{2} \mathrm{H}_{2} / \mathrm{C}_{2} \mathrm{H}$ without plasma, figure 15 , is compared with the expected count ratio determined from calculated cross-sections for equations (3) and (4). The close fit confirms that the measured plasma-off $\mathrm{C}_{2} \mathrm{H}$ counts represent a derivative product created within the MEA rather than $\mathrm{C}_{2} \mathrm{H}$ from within the chamber. Thus the use of MEA for $\mathrm{C}_{2} \mathrm{H}$ detection has been shown to be highly problematic due to orifice, sticking and filament ionization effects.

This raises the question as to whether any $\mathrm{C}_{2} \mathrm{H}$ generation from $\mathrm{C}_{2} \mathrm{H}_{2}$ occurs within the plasma volume and, if so, whether it is sufficient to account for the observed fall in pressure. Figure 16 shows neutral count rates, measured at electron energy of $70 \mathrm{eV}$, for masses 24 to 28 , at base pressure $\left(10^{-6}\right.$ Torr) and at $10 \mathrm{mTorr}$, with and without plasma. At 10 mTorr, with the plasma-off, we assume all neutrals except $\mathrm{C}_{2} \mathrm{H}_{2}$ are caused by ionization within the MEA. At plasma turn-on $\mathrm{C}_{2} \mathrm{H}_{2}$ and $\mathrm{C}_{2} \mathrm{H}$ neutral fractions drop; $\mathrm{C}_{2} \mathrm{H}_{2}$ by a factor of 30 but $\mathrm{C}_{2} \mathrm{H}$ by only a factor of 10 , indicating detection of some of the $\mathrm{C}_{2} \mathrm{H}$ formation within plasma. We estimate the film growth rate on the chamber walls due $\mathrm{C}_{2} \mathrm{H}$ deposition, 


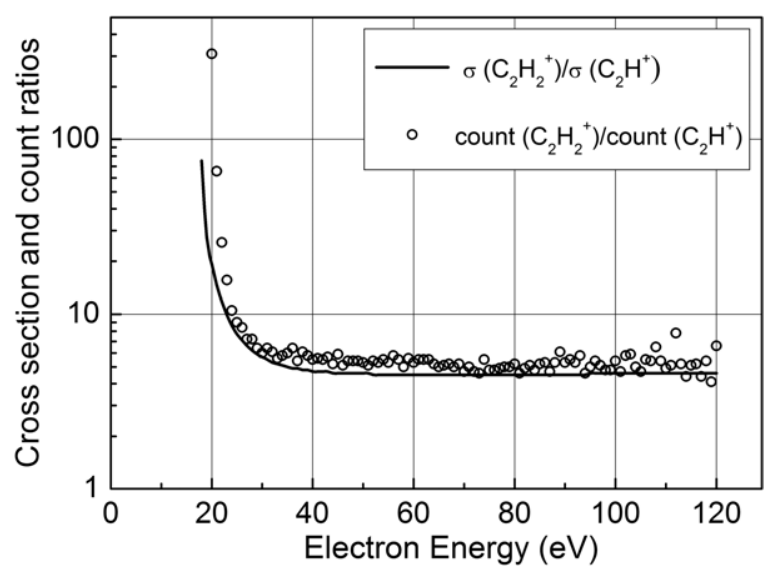

Figure 15. Measured $\mathrm{C}_{2} \mathrm{H}_{2} / \mathrm{C}_{2} \mathrm{H}$ count ratios versus MEA electron ionizer energy in the ICP: $10 \mathrm{mTorr}_{2} \mathrm{C}_{2}$ : Ar (flow ratio $2: 1$ ), and plasma-off. The line shows the ratio calculated from the cross-sections for equations (3) and (4).

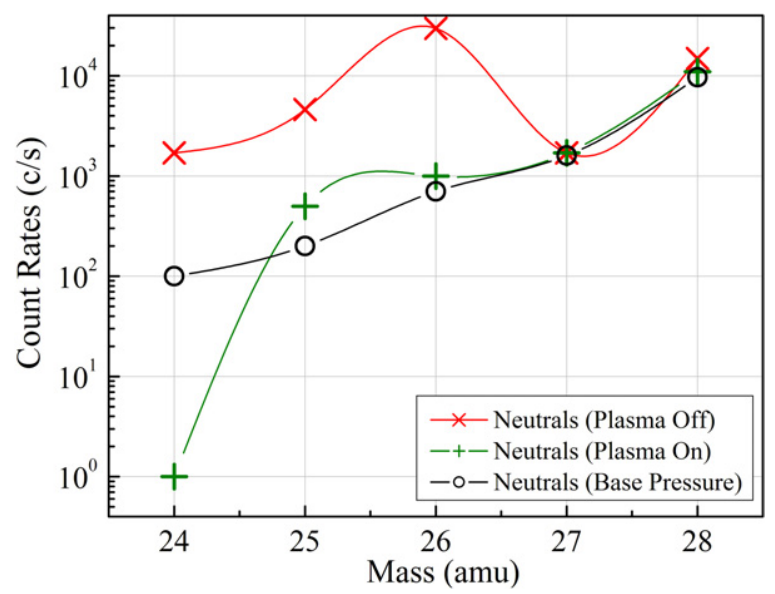

Figure 16. Neutral mass spectra around mass 26. Green: ICP

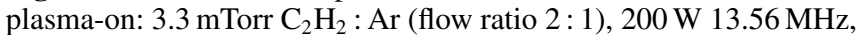
electrode grounded. Red: ICP plasma-off: $10 \mathrm{mTorr}^{\mathrm{C}_{2} \mathrm{H}_{2}}$ : Ar (flow ratio $2: 1)$ and black: base pressure $\left(2 \times 10^{-6}\right.$ Torr $)$.

assuming $100 \%$ conversion from $\mathrm{C}_{2} \mathrm{H}_{2}$, to be approximately $2 \mathrm{~nm} \mathrm{~s}^{-1}$, in good agreement with measured substrate film growth rates of $1 \mathrm{~nm} \mathrm{~s}^{-1}$ [33]. Note that ion species detection in MEA IE mode is not subject to this effect since the electron filament is turned off for these measurements.

\subsection{CCP neutral species}

The neutral species variation with pressure has been classified into two families: the first, with densities approximately proportional to pressure, appears as near horizontal lines in figure 2(a). The second family, figure 2(b), shows a reduction in normalized count rate with increasing pressure; however, this fall is not as steep as one would get from a species with constant count at all pressures.

We would expect the input gases to be in the first family, but the behaviour of the other species in this family is nontrivial. Excluding recombination, a first order approximation from particle balance gives the count rates normalized to pressure:

$$
\frac{n_{\mathrm{c}}}{n_{0}}=\frac{n_{\mathrm{e}} n_{\mathrm{p}} k}{n_{0} L} .
$$

The rate coefficient for the particular reaction is $k$ and $L$ is an assumed constant loss factor; $n_{0}, n_{\mathrm{e}}, n_{\mathrm{p}}$ and $n_{\mathrm{c}}$ are total neutral, electron, parent and child species number densities, respectively. For first generation products, $n_{\mathrm{p}} \propto n_{0}$, so we deduce that the product $n_{\mathrm{e}} k$ is almost constant for these species across the pressure range investigated. The second family, $\mathrm{H}_{2} \mathrm{O}, \mathrm{OH}, \mathrm{CO}_{2}$ and $\mathrm{ArH}$ in figure $2(b)$, is almost certainly due to impurities, and the variation with pressure, figure $2(b)$, suggests they are released from the chamber walls rather than being present in the $\mathrm{C}_{2} \mathrm{H}_{2}$ feedstock or from leaks.

Macek and Cekada [24] used mass spectrometry to measure species abundances and postulated relevant reactions. They observed atomic hydrogen to be the dominant neutral whereas in our case it is $\mathrm{C}_{2} \mathrm{H}_{2}$ followed by Ar. However, Macek's triode ion plating system contained significant $\mathrm{Ti}$ evaporant species used for the deposition of $\mathrm{TiC}$ in $\mathrm{Ar}+\mathrm{C}_{2} \mathrm{H}_{2}$ working gas which may reduce the $\mathrm{C}_{2} \mathrm{H}_{2}$ abundance. In our study, the most abundant child molecule is $\mathrm{C}_{2} \mathrm{H}_{4}$ (figures $2(a)$ and $5(b)$ ), which can be formed by the electron collisional dissociation of $\mathrm{C}_{2} \mathrm{H}_{6}$ [41] equation (6).

$$
\mathrm{e}+\mathrm{C}_{2} \mathrm{H}_{6} \rightarrow \mathrm{C}_{2} \mathrm{H}_{4}+\mathrm{H}_{2}+\mathrm{e} .
$$

$\mathrm{C}_{2} \mathrm{H}_{6}$ is not particularly abundant in our CCP and other production mechanisms may also need to be considered. Impurity $\mathrm{C}_{2} \mathrm{H}_{4}$ is reported to be present at $\sim 1 \%$ concentration in standard commercial grade acetylene, nevertheless with pure grade $\mathrm{C}_{2} \mathrm{H}_{2}$, the plasma formation of $\mathrm{C}_{2} \mathrm{H}_{4}$ has been experimentally observed and is considered an important precursor to $\mathrm{C}_{4} \mathrm{H}_{4}$ formation [71].

Deschenaux's [20] experimental observations, in pure $\mathrm{C}_{2} \mathrm{H}_{2} \mathrm{CCP}$, have shown a similar spectrum of major neutrals namely $\mathrm{H}_{2}, \mathrm{CH}, \mathrm{C}_{2}, \mathrm{C}_{2} \mathrm{H}, \mathrm{C}_{2} \mathrm{H}_{2}, \mathrm{C}_{2} \mathrm{H}_{3}, \mathrm{C}_{2} \mathrm{H}_{4}, \mathrm{C}_{4}, \mathrm{C}_{4} \mathrm{H}, \mathrm{C}_{4} \mathrm{H}_{2}$ and $\mathrm{C}_{4} \mathrm{H}_{3}$ out of which $\mathrm{H}_{2}, \mathrm{C}_{4} \mathrm{H}, \mathrm{C}_{4} \mathrm{H}_{2}$ were the new species produced but no $\mathrm{C}, \mathrm{CH}_{3}$ and $\mathrm{C}_{4} \mathrm{H}_{4}$ were observed. De Bleecker et al [21] have used Deschenaux's data to perform kinetic models and from these has predicted the formation of high mass hydrocarbon species at similar ratios to our $\mathrm{C}_{4} \mathrm{H}_{2} / \mathrm{C}_{2} \mathrm{H}_{2}$ ratio. Heavy species, reported in [21], have not been observed in our case and this may be due to the inhibition of the various polymerization reactions by, for example, the presence of argon species which can lead to the charge exchange reaction [47].

$$
\mathrm{Ar}^{+}+\mathrm{C}_{2} \mathrm{H}_{2} \rightarrow \mathrm{C}_{2} \mathrm{H}_{2}^{+}+\mathrm{Ar}
$$

with a measured reaction rate coefficient $6 \times 10^{-18} \mathrm{~m}^{3} \mathrm{~s}^{-1}$ [47].

In our case, neutral species were also investigated at fixed pressure and varying bias. Neutrals other than primary gas inputs were detected by the mass analyser with the plasmaoff, and these can be attributed to production within the MEA. The production of $\mathrm{C}_{4} \mathrm{H}_{2}$ and $\mathrm{C}_{4} \mathrm{H}_{4}$ in the plasma indicates that carbon triple bonding remains mainly intact, i.e. which supports the findings by Deschenaux et al [20] where spectra are bunched around even number carbon atoms. A potential 
reaction for the production of $\mathrm{C}_{4} \mathrm{H}_{2}$ in the plasma is the condensation reaction $[21,70,71]$.

$$
\mathrm{C}_{2} \mathrm{H}+\mathrm{C}_{2} \mathrm{H}_{2} \rightarrow \mathrm{C}_{4} \mathrm{H}_{2}+\mathrm{H}
$$

while $\mathrm{C}_{4} \mathrm{H}_{4}$ is derived from [71]

$$
\mathrm{C}_{2} \mathrm{H}+\mathrm{C}_{2} \mathrm{H}_{4} \rightarrow \mathrm{C}_{4} \mathrm{H}_{4}+\mathrm{H} \text {. }
$$

The probability of the $\mathrm{C}_{2} \mathrm{H}+\mathrm{C}_{2} \mathrm{H}_{2}$ reaction (equation (8)) in the CCP reactor compared with wall loss requires consideration of characteristic reaction and diffusion times. The characteristic diffusion time $\tau_{\mathrm{D}}$ is

$$
\tau_{\mathrm{D}}=\frac{\lambda_{\mathrm{CD}}^{2}}{4 D} .
$$

where $\lambda_{\mathrm{CD}}$ is the collisional diffusion length

$$
\lambda_{\mathrm{CD}}=\frac{L_{\mathrm{CHAR}}^{2}}{\lambda_{\mathrm{EL}}}
$$

with $L_{\mathrm{CHAR}}=32 \mathrm{~mm}$ for the $\mathrm{CCP}$ chamber. The $\mathrm{C}_{2} \mathrm{H}$ mean free path, $\lambda_{\mathrm{EL}}$, is estimated by assuming the values of the elastic scattering cross-sections for $\mathrm{C}_{2} \mathrm{H}+\mathrm{C}_{2} \mathrm{H}$ and $\mathrm{C}_{2} \mathrm{H}+\mathrm{Ar}$ are $5 \times 10^{-19} \mathrm{~m}^{2}$, similar to those published for $\mathrm{Ar}+\mathrm{Ar}$. The diffusion coefficient, $D$, is given by

$$
D=\frac{\pi}{8} \lambda_{\mathrm{EL}}^{2} v_{\mathrm{C}}
$$

where $\nu_{\mathrm{C}}$ is the elastic collision frequency, and the characteristic reaction time $\tau_{\mathrm{R}}$ is

$$
\tau_{\mathrm{R}}=\frac{1}{\sum k n_{\mathrm{T}}}
$$

where $k$ is the rate constant for the particular reaction. The target number density, $n_{\mathrm{T}}$, was determined from neutral species mass spectra fraction and measured pressure.

For the $\mathrm{C}_{2} \mathrm{H}+\mathrm{C}_{2} \mathrm{H}_{2}$ reaction (equation (8)) in the CCP, the analysis gives $\tau_{\mathrm{D}} \approx 60 \mu \mathrm{s}$. The characteristic reaction times were calculated for initial turn-on $\left(\tau_{\mathrm{R} 1}\right)$ and steady-state $\left(\tau_{\mathrm{R} 2}\right)$ conditions. The initial gas species mixture resulted in $\tau_{\mathrm{R} 1} \approx 100 \mu$ s (i.e. $\approx 2 \tau_{\mathrm{D}}$ ), and the steady-state mixture gives $\tau_{\mathrm{R} 2} \approx 500 \mu$ s (i.e. $\approx 10 \tau_{\mathrm{D}}$ ) thus indicating a low probability for the reaction (equation (8)) and the dominance of diffusion once steady-state conditions are reached. At turnon, however, whilst most $\mathrm{C}_{2} \mathrm{H}$ is lost through diffusion, a significant proportion of $\mathrm{C}_{2} \mathrm{H}$ undergoes the reaction.

\subsection{CCP ionic species}

The dominant ion species at $\left.30 \mathrm{eV} \mathrm{IE} \mathrm{(} V_{\mathrm{dc}}=450 \mathrm{~V}, 6 \mathrm{mTorr}\right)$ shown in figure 3 are $\mathrm{C}_{2} \mathrm{H}_{2}^{+}$followed by $\mathrm{Ar}^{+}, \mathrm{C}_{4} \mathrm{H}_{2}^{+}$and $\mathrm{C}_{4} \mathrm{H}_{3}^{+}$. Energy integrated ion counts of the energy distribution show the ranking to be $\mathrm{C}_{2} \mathrm{H}_{2}^{+}$followed by $\mathrm{C}_{4} \mathrm{H}_{2}^{+}$then $\mathrm{Ar}^{+}$ and a later IED study confirmed this. These three species account for over $90 \%$ of all ions and likely production mechanisms for the $\mathrm{C}_{4} \mathrm{H}_{x}^{+}$family are electron impact ionization of neutrals from equations (8) and (9). Deschenaux et al [20] observe significant species counts, however, from the heavy ion families up to $\mathrm{C}_{15} \mathrm{H}_{y}$. De Bleecker et al [21] have used Deschenaux's data to construct a suitable polymerization model to account for these heavy ions. For ions, as with neutrals, we also note the carbon triple bonding remains mainly intact (even numbered carbon atom spectra), in agreement with [23].

\subsection{ICP neutral species}

The five dominant neutral species in the plasma (figure 7) are masses 30, 44, 18, 28 and 40 amu. Without bias, the $\mathrm{Ar}: \mathrm{C}_{2} \mathrm{H}_{2}$ ratio is very large $(\sim 300)$, this falls to $\sim 5-10$ on application of both 8.311 and $27 \mathrm{MHz}$ bias; however, it rises again under the high pressure and frequency condition. The greatest change in species counts upon plasma ignition is observed for masses 24 to $26 \mathrm{amu}$, reducing by two orders of magnitude, as noted above. Significant increases in masses 37 and 48 were also noted as well as the formation of new species at masses 68 and 69 amu. At higher frequency, these heavier species are suppressed. Significant reduction in $\mathrm{C}$ and $\mathrm{CH}$ concentrations was observed as pressure was raised from 3.3 to 25 mTorr. $\mathrm{C}_{2}$ is only observed in the plasma-off state.

Hydrogen species $\left(\mathrm{H}, \mathrm{H}_{2}\right.$ and $\left.\mathrm{H}_{3}\right)$ were observed in small quantities; atomic hydrogen appearing close to the detection limit while $\mathrm{H}_{3}$ was observed only at $27 \mathrm{MHz}$ and $\mathrm{H}_{2}$ was approximately constant across all conditions. Abstraction of hydrogen via electron dissociation of $\mathrm{C}_{2} \mathrm{H}_{2}$ [38], equation (1), should lead to significant atomic hydrogen; however, atomic $\mathrm{H}$ has a high surface loss rate $[32,40]$, and is known to create dangling bonds by abstraction of surface bonded hydrogen, which desorbs as $\mathrm{H}_{2}$ or chemisorbs at dangling bonds formed by ion bombardment. Formation of $\mathrm{H}_{2}$ may therefore be accounted for by $\mathrm{H}$-atom and radical reactions at surfaces and also occur from electron dissociation of hydrocarbons [41]:

$$
\begin{gathered}
\mathrm{e}+\mathrm{C}_{2} \mathrm{H}_{2 n} \rightarrow \mathrm{C}_{2} \mathrm{H}_{n-2}+\mathrm{H}_{2}+\mathrm{e} \\
\mathrm{e}+\mathrm{C}_{2} \mathrm{H}_{2 n} \rightarrow \mathrm{C}_{2} \mathrm{H}_{n-3}+\mathrm{H}_{2}+\mathrm{H}+\mathrm{e} .
\end{gathered}
$$

The $\mathrm{H}_{3}$ signal is relatively low and somewhat sporadic; the probable source is $\mathrm{H}_{3}^{+}$produced within the MEA ionizer, e.g. via $\mathrm{H}_{2}+\mathrm{ArH}^{+} \Rightarrow \mathrm{Ar}+\mathrm{H}_{3}^{+}$[54], accelerated and collected. We also observe $\mathrm{H}_{3}^{+}$in IM mode when the ionizer is off, which suggests that similar reactions occur within the plasma or plasma sheath. Two less probable mechanisms which could add to the observed $\mathrm{H}_{3}$ signal are leakage of $\mathrm{H}_{3}^{+}$from the plasma through the MEA orifice and/or neutralization [48] of $\mathrm{H}_{3}^{+}$within the plasma or sheath. However, we consider it unlikely that $\mathrm{H}_{3}$ is a true plasma species.

The reaction paths for the formation of both $C$ [41] and $\mathrm{CH}$ may follow equations (12) to (14) and the calculated rates are shown in table 2

$$
\begin{gathered}
\mathrm{e}+\mathrm{C}_{2} \mathrm{H}_{2} \rightarrow \mathrm{C}+\mathrm{CH}_{2}+\mathrm{e} \\
\mathrm{e}+\mathrm{CH} \rightarrow \mathrm{C}+\mathrm{H}+\mathrm{e} \\
\mathrm{e}+\mathrm{C}_{2} \mathrm{H}_{2} \rightarrow 2 \mathrm{CH}+\mathrm{e} .
\end{gathered}
$$

The presence of $\mathrm{C}_{2}$ with no plasma is easily reconciled with production within the spectrometer as detailed above for $\mathrm{C}_{2} \mathrm{H}$. 
Table 1. Ionization, metastable and dissociation threshold energies for reactions relevant to $\mathrm{Ar}^{+}$and $\mathrm{C}_{2} \mathrm{H}_{2}^{+}$abundance.

\begin{tabular}{lcll}
\hline Reactions & $E_{\text {th }}(\mathrm{eV})$ & Equation & Reference \\
\hline $\mathrm{e}+\mathrm{Ar} \rightarrow \mathrm{Ar}^{+}+2 \mathrm{e}$ & 15.76 & $(15)$ & {$[50]$} \\
$\mathrm{e}+\mathrm{Ar} \rightarrow \mathrm{Ar}^{\mathrm{m}}+\mathrm{e}$ & 11.55 & $(16)$ & {$[51]$} \\
$\mathrm{e}+\mathrm{Ar}^{\mathrm{m}} \rightarrow \mathrm{Ar}^{+}+2 \mathrm{e}$ & 4.21 & $(17)$ & {$[51]$} \\
$\mathrm{e}+\mathrm{C}_{2} \mathrm{H}_{2} \rightarrow \mathrm{C}_{2} \mathrm{H}_{2}^{+}+2 \mathrm{e}$ & 11.41 & $(3)$ & {$[49]$} \\
$\mathrm{e}+\mathrm{C}_{2} \mathrm{H}_{2} \rightarrow \mathrm{C}_{2} \mathrm{H}+\mathrm{H}+\mathrm{e}$ & 7.5 & $(1)$ & {$[21]$} \\
\hline
\end{tabular}

The lack of observed species once the plasma is ignited is in accordance with the model predictions of De Bleecker et al [21]. We may also expect high loss rates at surfaces for $\mathrm{C}, \mathrm{CH}$ and $\mathrm{C}_{2}$ as sticking coefficients are expected to approach 1 [42].

As in the CCP case, the presence of heavy $\mathrm{C}_{2 x} \mathrm{H}_{y}(x=2$, 3 , 4, etc) species is much less than observed by Deschenaux et al [20] and predicted by the model in [21]. As noted earlier, these heavy species are mainly initiated via $\mathrm{C}_{2} \mathrm{H}-$ $\mathrm{C}_{2} \mathrm{H}_{2}$ reactions and are precursors to particle formation which we consider unlikely in our case due to the low acetylene density and the reduction in electron temperature on addition of acetylene [69]. A significant $(\times 2$ to $\times 6)$ increase in the $\mathrm{ArH}$ neutral is observed post ignition and is assumed to come from the ionic species which will be considered in the next section.

Similar analysis to that used in section 4.1 was also applied to the ICP to compare $\mathrm{C}_{2} \mathrm{H}$ loss via diffusion to the total loss rate from several reactions (De Bleeker et al [21], table 4 reactions (1) to (5)). For the low pressure (3.3 mTorr) measurements $\tau_{\mathrm{D}} \approx 200 \mu \mathrm{s}, \tau_{\mathrm{R} 1} \approx 70 \mu \mathrm{s}$ and $\tau_{\mathrm{R} 2} \approx 5000 \mu \mathrm{s}$. Thus $\tau_{\mathrm{R} 2} \approx 25 \tau_{\mathrm{D}}$ and $\tau_{\mathrm{R} 1} \approx 0.35 \tau_{\mathrm{D}}$. Diffusion dominates in the steady state, as in the CCP case, but reaction chemistry dominates at turn-on. At higher pressures (25 mTorr) $\tau_{\mathrm{D}} \approx$ $13 \mathrm{~ms}, \tau_{\mathrm{R} 1} \approx 18 \mu \mathrm{s}$ and $\tau_{\mathrm{R} 2} \approx 9 \mathrm{~ms}$. Thus $\tau_{\mathrm{R} 2} \approx 0.5 \tau_{\mathrm{D}}$ and $\tau_{\mathrm{R} 1} \approx 0.001 \tau_{\mathrm{D}}$ and at this pressure, the reaction chemistry dominates at all stages.

\subsection{ICP ionic species}

The dominant ionic species is $\mathrm{Ar}^{+}$even though the threshold ionization energy of $\mathrm{C}_{2} \mathrm{H}_{2}$ [49] is lower than $\mathrm{Ar}$ [50]. The species with the next highest abundance is $\mathrm{ArH}^{+}$. This is obviously a consequence of the loss of $\mathrm{C}_{2} \mathrm{H}_{2}$ neutrals. However, although we also observe $\mathrm{C}_{2} \mathrm{H}_{2}$ neutral loss mechanisms in the CCP, we do not observe the same $\mathrm{Ar}^{+}$ dominance. From table 1, the ionization threshold for $\mathrm{C}_{2} \mathrm{H}_{2}^{+}$[49] (equation (3)) is similar to that of $\mathrm{Ar}^{+}$via the metastable pathway [51] equation (16), table 1. Thus, the reaction probabilities for both hydrogen extraction from $\mathrm{C}_{2} \mathrm{H}_{2}$ (equation (1)), typically requiring sufficient electrons of energies around $4 \mathrm{eV}$, and argon ionization (equations (15) to (17)) must be lower in a CCP.

ICPs are known to produce electron densities typically 1-2 orders of magnitude greater than CCPs for similar power inputs. Furthermore, EEDF measured in the ICPs indicate a greater proportion of electrons of intermediate energy $(3-11 \mathrm{eV})$ [11] compared with the bi-Maxwellian EEDFs expected in CCPs. This leads to greater $\mathrm{Ar}^{+}$densities in pure argon for ICPs. These conditions also favour reactions in equation (1) over equation (3), thus the greater loss of $\mathrm{C}_{2} \mathrm{H}_{2}$ in the ICP is expected. This explains the observed dependence in $\mathrm{Ar}^{+}: \mathrm{C}_{2} \mathrm{H}_{2}^{+}$ratio with plasma excitation mode. In fact, in the $\mathrm{CCP}$, higher powers resulted in greater fall in pressure and hence $\mathrm{C}_{2} \mathrm{H}_{2}$, figures 8 and 9. Under the experimental conditions used here, the differences in plasma volume and the remote sampling position of the MEA in the CCP chamber would further contribute to this.

The production of $\mathrm{ArH}^{+}$ion has also been reported elsewhere [11,52] and a number of production mechanisms have been proposed [11]. All reactions involve an argon ion colliding with either a hydrocarbon molecule or hydrogen. In their ICP system with $\mathrm{CH}_{4} / \mathrm{Ar}$, Jie et al [11] observed an abundance of atomic $\mathrm{H}$ but they note that the argon ion attachment with atomic hydrogen has a low cross-section [53]. The alternative reaction involving argon ions and hydrogen molecules, equation (18), is more plausible due to the observed $\mathrm{H}_{2}$ count in our system, in agreement with that stated by Jie et al [11] and Rusu et al [52].

$$
\mathrm{Ar}^{+}+\mathrm{H}_{2} \rightarrow \mathrm{ArH}^{+}+\mathrm{H} \text {. }
$$

This reaction is fast $\left(k \sim 1 \times 10^{-15} \mathrm{~m}^{3} \mathrm{~s}^{-1}\right)$ [54] and suppresses the $\mathrm{H}_{2}$ concentration in the plasma [75].

The only other report on $\mathrm{C}_{2} \mathrm{H}_{2} / \mathrm{Ar}$ ionic species [24] is in an arc-filament $\mathrm{Ti}$ deposition plasma operated at $\sim 10 \mathrm{mTorr}$ where they observed $\mathrm{Ar}^{+} / \mathrm{C}_{2} \mathrm{H}_{2}^{+} \gg 1$. The dominant ion, however, in this case is $\mathrm{C}^{+}$.

A limited number of experiments were carried out at much higher pressure (120 mTorr). Post-ignition, the pressure drop results in an argon-dominated plasma as before and $\mathrm{Ar}^{+}$is the dominant ion. The main carbon bearing ion species is $\mathrm{C}^{+}$, figure 14. The threshold energy required for the formation of $\mathrm{C}^{+}$via dissociative ionization of $\mathrm{C}_{2} \mathrm{H}_{2}$, (equation (19) plus similar), is near $20 \mathrm{eV}[41,56]$,

$$
\mathrm{e}+\mathrm{C}_{2} \mathrm{H}_{2} \rightarrow \mathrm{C}^{+}+\mathrm{CH}_{2}+2 \mathrm{e}
$$

which is much greater than that for $\mathrm{C}_{2} \mathrm{H}_{2}^{+}(11.4 \mathrm{eV}), \mathrm{C}_{2} \mathrm{H}^{+}$ $(16.5 \mathrm{eV})$ and $\mathrm{C}_{2}^{+}(17.5 \mathrm{eV})$ [56]. Measurements in a similar system for pure argon indicated higher plasma density and lower electron temperature as the pressure is increased $[57,58]$. The reduction in temperature should inhibit $\mathrm{C}^{+}$production while $\mathrm{Ar}^{+}$-based reactions, e.g. equation (19), need to be energetic and hence occur in the sheath [47].

$$
\mathrm{Ar}_{\text {fast }}^{+}+\mathrm{C}_{2} \mathrm{H}_{2} \rightarrow \mathrm{C}^{+}+\mathrm{CH}_{2}+\mathrm{Ar} \text {. }
$$

The observed variation in ion flux with $V_{\text {bias }}$ is not consistent with the conventional Bohm theory [55] where flux depends only on ion density at the sheath $\left(n_{\mathrm{i}}\right)$ and electron temperature $\left(T_{\mathrm{e}}\right)$. The contribution of the rf bias field to local ionization is an obvious source of enhanced plasma density near the bias electrode. Further, the effect on local electron temperature may play a part. Any such changes, however, must be limited in extent since the Langmuir probe measurements $(107 \mathrm{~mm}$ above the bias electrode) showed that the bulk plasma was only slightly affected by $V_{\text {bias }}$ up to $100 \mathrm{~V}$. Methods of direct total ion flux measurements at the substrate are currently under investigation. 


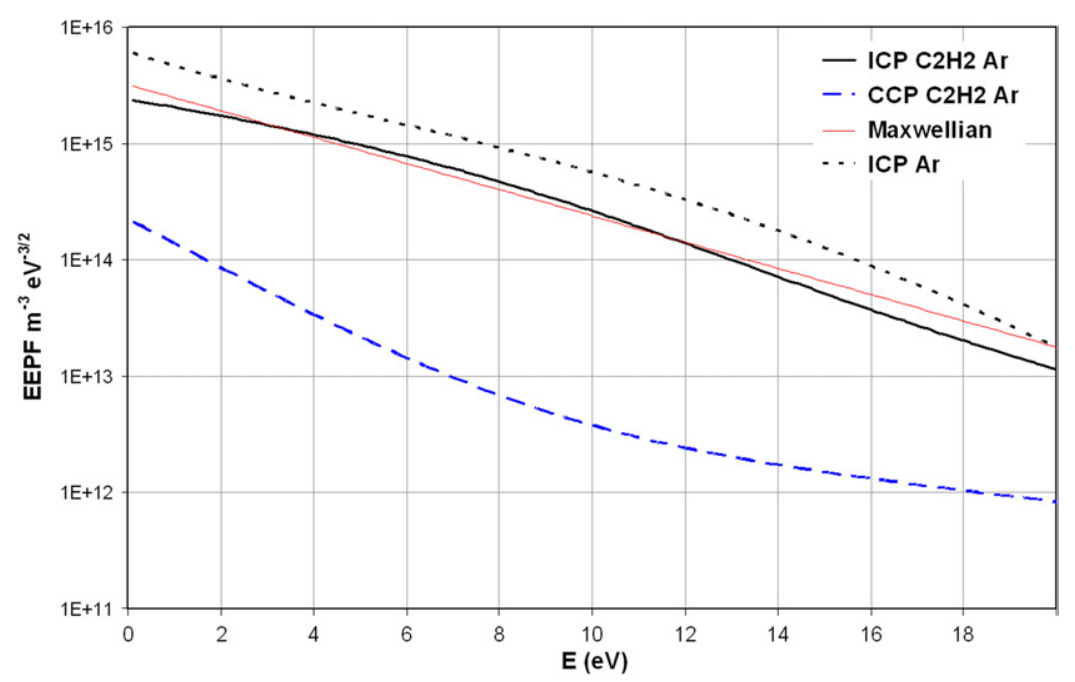

Figure 17. EEPFs: ICP, $200 \mathrm{~W} 13.56 \mathrm{MHz}$ and $V_{\text {bias }}=0 \mathrm{~V}$. Black dotted line: $10 \mathrm{mTorr}$ pure Ar, thick black line: $3.3 \mathrm{mTorr} \mathrm{C}_{2} \mathrm{H}_{2}: \mathrm{Ar}($ flow ratio $2: 1$ ), for comparison we also show a Maxwellian EEPF (thin straight red line). This has the same electron density and temperature as that measured for the $\mathrm{C}_{2} \mathrm{H}_{2}$ : Ar mixture in the ICP (thick line). The dashed blue line shows the estimated EEPF for a $\mathrm{C}_{2} \mathrm{H}_{2}: \mathrm{Ar} C C P$.

\subsection{Rates and rate coefficients}

In order to evaluate the various reaction possibilities we have considered the available rate coefficients and associated crosssections [23, 27, 35, 44, 46, 47, 50, 51, 54, 59-62]. For the ICP electron collisions we have used our measured EEDFs to determine the rate coefficients. The associated probability functions (EEPFs) are shown in figure 17, where $\operatorname{EEPF}(E)=$ $\operatorname{EEDF}(E) / \sqrt{E}$. Analysis for pure Ar (thick dotted line) gives $n_{\mathrm{e}}=4.3 \times 10^{16} \mathrm{~m}^{-3}$ and the expected [35,63] combination of Maxwellian and Druyvesteyn populations. For the mixture, the fraction of final $\mathrm{C}_{2} \mathrm{H}_{2}$ is $\sim 5 \%$ (post pressure drop) and the EEPF (thick solid line) shows a very similar form but with the number density $n_{\mathrm{e}}$ reduced to $2.3 \times 10^{16} \mathrm{~m}^{-3}$. A pure Maxwellian EEPF (thin straight line) is shown for comparison. In the absence of CCP measurements, we have assumed a bi-Maxwellian EEPF (dashed black line) with $n_{\mathrm{e}}$ reduced by a factor of 30 compared with the $\mathrm{C}_{2} \mathrm{H}_{2}$ : Ar ICP. Note that non-Maxwellian EEDFs are often characterized by an effective temperature $\left\langle T_{\mathrm{e}}\right\rangle$ [63]; detailed analysis of the EEDFs gave $\left\langle T_{\mathrm{e}}\right\rangle=3.85 \mathrm{eV}$ for all EEPFs shown in figure 17 . The rate coefficients $(k)$ and rates $(r)$ for $\mathrm{C}_{2} \mathrm{H}_{2}$ : Ar mixtures were calculated using the convolution of the energy-dependent EEDFs and cross-sections [41] and the outcomes are listed in table 2. For comparison we also show $f$, the ratio of rate coefficient derived from measured (or assumed) EEDFs to those from the Maxwellian distribution with the same $\left\langle T_{\mathrm{e}}\right\rangle$. We note that models (for pure $\mathrm{C}_{2} \mathrm{H}_{2}$ ) by Doyle [22] appear to be based on assumed ratios of rate coefficient while De Bleeker et al [21] and Bera et al [61] calculate EEDFs to determine their rates.

Rate coefficients for many of the heavy-heavy particle reactions mentioned in the text are also included in table 2. The species densities used in these evaluations for rate calculations are either measured or estimated from mass spectra measurements. ICP reaction rate coefficients are generally about $20 \%$ less than those calculated using a pure Maxwellian, whilst the assumed CCP EEDF results in significantly higher rates. Of particular note is equation (8) which corresponds to the high abundance of $\mathrm{C}_{4} \mathrm{H}_{2}$ in figure 4 . The rates also indicate that the main argon ionization route in the ICP is via metastables whereas in the $\mathrm{CCP}$ direct ionization dominates. In the ICP, the loss rates of $\mathrm{C}_{2} \mathrm{H}_{2}$ via equations (1) and (2) are significantly greater than through ionization. The measured abundances of $\mathrm{C}_{4} \mathrm{H}_{x}$ species (mass 49 to mass 53) matched the calculated rates for both $\mathrm{CCP}$ and ICP.

\section{Conclusions}

The neutral and positive ionic species measured in the CCP and ICP are the first such measurements published with $\mathrm{C}_{2} \mathrm{H}_{2}$ : Ar as the working gas under bias and pressure conditions suited for diamond-like carbon deposition. We have successfully addressed the traditional challenges and difficulties inherent in in situ diagnostics of deposition plasmas. In our companion paper [33] we investigate the ion energy distributions for each system and compare with the characteristics of deposited carbon films, under the same plasma conditions.

The drastic drop in chamber pressure at $\mathrm{C}_{2} \mathrm{H}_{2}$ : Ar plasma turn-on can be explained in terms of the electron dissociation of $\mathrm{C}_{2} \mathrm{H}_{2}$, which leads to $\mathrm{C}_{2} \mathrm{H}$ formation. The $\mathrm{C}_{2} \mathrm{H}$ radical has a high surface loss probability factor [42] and is therefore lost to the chamber walls. It is thus the major component of film growth. The pressure drop along with $\mathrm{C}_{2} \mathrm{H}_{2}$ depletion was most noticeable in the ICP because of the increased number density and the EEDF with sufficient electrons of energy $E, 11 \mathrm{eV}>E>7.6 \mathrm{eV}$, to lead to an argon dominated plasma irrespective of input gas ratio. The detection of $\mathrm{C}_{2} \mathrm{H}$ was inhibited due to high surface loss probability and a significant proportion of the observed $\mathrm{C}_{2} \mathrm{H}$ neutrals is due to the species generation within MEA. Depletion of the acetylene precursor was further investigated using infrared spectroscopy, where transient production of $\mathrm{CH}_{4}$, showing a hitherto unreported $\mathrm{C}_{2} \mathrm{H}_{2}-\mathrm{CH}_{4}$ relationship, was also observed. This transient $\mathrm{CH}_{4}$ signal then decayed to 
Table 2. Rate coefficients $k$ and rates $r$ for selected reactions in the $\mathrm{C}_{2} \mathrm{H}_{2}$ : Ar mixture ICP (I) and CCP (C), $f$ is the ratio of rate coefficient derived from realistic EEDFs to those from the Maxwellian distribution with the same $\left\langle T_{\mathrm{e}}\right\rangle$.

\begin{tabular}{|c|c|c|c|c|c|c|}
\hline Reaction & Equation & & $k\left(\mathrm{~m}^{3} \mathrm{~s}^{-1}\right)$ & $f$ & $r\left(\mathrm{~m}^{-3} \mathrm{~s}^{-1}\right)$ & Reference \\
\hline \multirow[t]{2}{*}{$\mathrm{e}+\mathrm{Ar} \rightarrow \mathrm{Ar}^{+}+2 \mathrm{e}$} & $(15)$ & I & $4.5 \times 10^{-16}$ & 0.66 & $5.5 \times 10^{19}$ & {$[50]$} \\
\hline & & $\mathrm{C}$ & $3.6 \times 10^{-15}$ & 5.16 & $1.5 \times 10^{20}$ & \\
\hline \multirow{2}{*}{$\mathrm{e}+\mathrm{C}_{2} \mathrm{H}_{2} \rightarrow \mathrm{C}_{2} \mathrm{H}_{2}^{+}+2 \mathrm{e}$} & (3) & I & $1.0 \times 10^{-15}$ & 0.67 & $3.0 \times 10^{16}$ & {$[41]$} \\
\hline & & $\mathrm{C}$ & $6.0 \times 10^{-15}$ & 3.82 & $2.6 \times 10^{20}$ & \\
\hline \multirow[t]{2}{*}{$\mathrm{e}+\mathrm{Ar} \rightarrow \mathrm{Ar}^{\mathrm{m}}+\mathrm{e}$} & (16) & I & $1.6 \times 10^{-16}$ & 0.71 & $2.0 \times 10^{19}$ & [50] \\
\hline & & $\mathrm{C}$ & $5.4 \times 10^{-16}$ & 2.35 & $2.3 \times 10^{19}$ & \\
\hline \multirow{2}{*}{$\mathrm{e}+\mathrm{Ar}^{\mathrm{m}} \rightarrow \mathrm{Ar}^{+}+2 \mathrm{e}$} & $(17)$ & I & $6.0 \times 10^{-14}$ & 1.02 & $3.6 \times 10^{20^{\mathrm{a}}}$ & {$[50]$} \\
\hline & & $\mathrm{C}$ & $4.7 \times 10^{-14}$ & 0.80 & $2.3 \times 10^{19^{\mathrm{a}}}$ & \\
\hline \multirow[t]{2}{*}{$\mathrm{e}+\mathrm{C}_{2} \mathrm{H}_{2} \rightarrow \mathrm{C}_{2} \mathrm{H}+\mathrm{H}+\mathrm{e}$} & (1) & I & $1.5 \times 10^{-15}$ & 0.80 & $2.8 \times 10^{19}$ & {$[41]$} \\
\hline & & $\mathrm{C}$ & $2.8 \times 10^{-15}$ & 1.53 & $1.3 \times 10^{20}$ & \\
\hline \multirow[t]{2}{*}{$\mathrm{e}+\mathrm{C}_{2} \mathrm{H}_{2} \rightarrow$ all dissociation } & (2) & I & $2.0 \times 10^{-15}$ & 0.79 & $3.8 \times 10^{19}$ & [41] \\
\hline & & $\mathrm{C}$ & $4.4 \times 10^{-15}$ & 1.77 & $2.0 \times 10^{20}$ & \\
\hline \multirow[t]{2}{*}{$\mathrm{e}+\mathrm{C}_{2} \mathrm{H}_{6} \rightarrow \mathrm{C}_{2} \mathrm{H}_{4}+\mathrm{H}_{2}+\mathrm{e}$} & (6) & I & $1.4 \times 10^{-14}$ & 0.99 & $7.3 \times 10^{21}$ & [41] \\
\hline & & $\mathrm{C}$ & $1.2 \times 10^{-14}$ & 0.82 & $1.5 \times 10^{18}$ & \\
\hline \multirow[t]{2}{*}{$\mathrm{C}_{2} \mathrm{H}+\mathrm{C}_{2} \mathrm{H}_{2} \rightarrow \mathrm{C}_{4} \mathrm{H}_{2}+\mathrm{H}$} & (8) & $\mathrm{I}$ & $5.8 \times 10^{-17}$ & & $7.2 \times 10^{18}$ & {$[62]$} \\
\hline & & $\mathrm{C}$ & & & $4.2 \times 10^{22}$ & \\
\hline $\mathrm{e}+\mathrm{C}_{2} \mathrm{H}_{2} \rightarrow \mathrm{C}_{2}+\mathrm{H}_{2}+\mathrm{e}$ & $(10)$ & I & $2.8 \times 10^{-16}$ & 0.75 & $5.4 \times 10^{18}$ & [41] \\
\hline $\mathrm{e}+\mathrm{C}_{2} \mathrm{H}_{4} \rightarrow \mathrm{C}_{2} \mathrm{H}_{2}+\mathrm{H}_{2}+\mathrm{e}$ & (10) & I & $2.3 \times 10^{-15}$ & 0.91 & $4.7 \times 10^{20}$ & [41] \\
\hline $\mathrm{e}+\mathrm{C}_{2} \mathrm{H}_{4} \rightarrow \mathrm{C}_{2} \mathrm{H}+\mathrm{H}_{2}+\mathrm{H}+\mathrm{e}$ & (11) & I & $1.8 \times 10^{-16}$ & 0.77 & $3.6 \times 10^{19}$ & {$[41]$} \\
\hline $\mathrm{e}+\mathrm{C}_{2} \mathrm{H}_{6} \rightarrow \mathrm{C}_{2} \mathrm{H}_{3}+\mathrm{H}_{2}+\mathrm{H}+\mathrm{e}$ & (11) & I & $6.5 \times 10^{-17}$ & 0.73 & $3.3 \times 10^{19}$ & {$[41]$} \\
\hline $\mathrm{e}+\mathrm{C}_{2} \mathrm{H}_{6} \rightarrow \mathrm{C}_{2} \mathrm{H}_{2}+2 \mathrm{H}_{2}+\mathrm{e}$ & (10) & I & $9.3 \times 10^{-16}$ & 0.87 & $4.8 \times 10^{20}$ & [41] \\
\hline $\mathrm{e}+\mathrm{H}_{2} \rightarrow \mathrm{H}+\mathrm{H}+\mathrm{e}$ & (21) & I & $1.7 \times 10^{-15}$ & 0.79 & $1.2 \times 10^{19^{\mathrm{b}}}$ & [41] \\
\hline $\mathrm{e}+\mathrm{C}_{2} \mathrm{H}_{2} \rightarrow \mathrm{C}+\mathrm{CH}_{2}+\mathrm{e}$ & (12) & I & $1.0 \times 10^{-16}$ & 0.72 & $1.2 \times 10^{17}$ & [41] \\
\hline $\mathrm{e}+\mathrm{C}_{2} \mathrm{H}_{2} \rightarrow 2 \mathrm{CH}+\mathrm{e}$ & (14) & I & $5.7 \times 10^{-17}$ & 0.70 & $2.2 \times 10^{17}$ & [41] \\
\hline $\mathrm{e}+\mathrm{CH}_{4} \rightarrow \mathrm{CH}_{2}+\mathrm{H}_{2}+\mathrm{e}$ & (22) & I & $5.1 \times 10^{-16}$ & 0.81 & $2.8 \times 10^{19}$ & [41] \\
\hline $\mathrm{Ar}^{+}+\mathrm{H}_{2} \rightarrow \mathrm{ArH}^{+}+\mathrm{H}$ & (18) & $\mathrm{I}$ & $1.7 \times 10^{-15}$ & & $3.9 \times 10^{18}$ & [54] \\
\hline $\mathrm{e}+\mathrm{C}_{2} \mathrm{H}_{2} \rightarrow \mathrm{C}^{+}+\mathrm{CH}_{2}+2 \mathrm{e}$ & (19) & I & $1.6 \times 10^{-18}$ & 0.72 & $3.0 \times 10^{16}$ & [41] \\
\hline $\mathrm{Ar}^{+}+\mathrm{C}_{2} \mathrm{H}_{2} \rightarrow \mathrm{C}^{+}+\mathrm{CH}_{2}+\mathrm{Ar}$ & (20) & I & $1 \times 10^{-19}$ & & $6.3 \times 10^{14^{c}}$ & [47] \\
\hline
\end{tabular}

a The argon metastable ionization rates are calculated for $\mathrm{Ar}^{\mathrm{m}}$ densities of $3 \times 10^{17} \mathrm{~m}^{-3}$ and

$7 \times 10^{17} \mathrm{~m}^{-3}$ for the ICP and CCP, respectively.

${ }^{\mathrm{b}}$ Underestimate since cross-sections for all underlying processes are not available.

c These reactions only occur in the sheath as they require fast ions.

almost zero at plasma equilibrium. The rise and fall time constants of $\mathrm{C}_{2} \mathrm{H}_{2}$ depletion were observed to be similar to those of the chamber pressure. Our spectra show heavier masses $(>\sim 50 \mathrm{amu})$ are not as abundant as those reported in the literature for pure $\mathrm{C}_{2} \mathrm{H}_{2}$, suggesting argon inhibition of polymerization. However, plasma transparency appeared to be diminished at higher pressures, possible evidence of nanoparticle suspensions; this was not observed at lower pressure. This study was focussed on positive ion and neutral species and negative ions were not investigated. An extensive set of rate coefficients and rates for the suggested electronneutral and heavy-heavy particle reactions is presented using, where appropriate, realistic EEDFs and measured species densities. These are useful for incorporation in future models. The limitations of mass spectrometry in high deposition flux plasmas, where the instrument orifice is necessarily restricted, have been highlighted. In particular, the orifice can act as a filter for high sticking coefficient species thus limiting the measurement accuracy.

These results have important implications for film growth studies and models, which are discussed in [33]. In particular, the argon species dominance in the ICP will result in an alternative ion-bombardment mechanism to current models while the proposed high conversion rate to $\mathrm{C}_{2} \mathrm{H}$ is also critical since this radical is thought to be the dominant $\mathrm{sp}^{3}$-promoting species during film formation.

\section{References}

[1] Maguire P D et al 2005 Diamond Relat Mater. 14 1277-88

[2] Tatsuta T, Tachibana K and Tsuji O 1994 Japan. J. Appl. Phys. Part 133 6341-9

[3] Valentini L, Kenny J M, Mariotto G and Tosi P 2001 J. Mater. Sci. 36 5295-300

[4] Ahmad I, Maguire P D, Lemoine P, Roy S S and McLaughlin J A 2004 Diamond Relat. Mater. 13 1346-9

[5] Okpalugo T I T, Ogwu A A, Maguire P D, McLaughlin J A D and Hirst D G 2004 Diamond Relat. Mater. 13 1088-92

[6] Okpalugo T I T, Ogwu A A, Maguire P D and McLaughlin J A D 2004 Biomaterials 25 239-45

[7] Okpalugo T I T, Maguire P D, Ogwu A A and McLaughlin J A D 2004 Diamond Relat. Mater. 13 1549-52

[8] Abbas G A, Papakonstantinou P, Okpalugo T I T, McLaughlin J A, Filik J and Harkin-Jones E 2005 Thin Solid Films 482 201-6

[9] Benedikt J, Letourneur K G Y, Wisse M, Schram D C and van de Sanden M C M 2002 Diamond Relat. Mater. 11 989-93

[10] Benedikt J, Woen R V, van Mensfoort S L M, Perina V, Hong J and van de Sanden M C M 2003 Diamond Relat. Mater. 12 90-7 
[11] Jie Z, T M, Ina, Reed A, Eli A, Dongping L and Ellen R F 2006 Plasma Sources Sci. Technol. 15 714-26

[12] Vanhulsel A, Celis J-P, Dekempeneer E, Meneve J, Smeets J and Vercammen K 1999 Diamond Relat. Mater. 8 1193-7

[13] Pappas D L and Hopwood J 1994 J. Vac. Sci. Technol. A 12 1576-82

[14] Robertson J 2002 Mater. Sci. Eng. R: Rep. R37 129-281

[15] Abbas G A, Papakonstantinou P and McLaughlin J A 2005 Appl. Phys. Lett. 87251918

[16] Abbas G A, McLaughlin J A and Harkin-Jones E 2004 Diamond Relat. Mater. 13 1342-5

[17] Jacob W 1998 Thin Solid Films 326 1-42

[18] Kojima H, Toyoda H and Sugai H 1989 Appl. Phys. Lett. 55 1292-4

[19] Toyoda H, Kojima H and Sugai H 1989 Appl. Phys. Lett. 54 1507-9

[20] Deschenaux C, Affolter A, Magni D, Hollenstein C and Fayet P 1999 J. Phys. D: Appl. Phys. 32 1876-86

[21] De Bleecker K, Bogaerts A and Goedheer W 2006 Phys. Rev. E 73026405

[22] Doyle J R 1997 J. Appl. Phys. 82 4763-71

[23] Vasile M J and Smolinsky G 1977 Int. J. Mass Spectrom. Ion Phys. 24 11-23

[24] Macek M and Cekada M 2004 Surf. Coat. Technol. 180-181 2-8

[25] Rangel E C, Da Cruz, Nilson C., Kayama M E, Rangel R C C, Marins N and Durrant S F 2004 Plasmas Polym. $91-22$

[26] Herrebout D, Bogaerts A, Gijbels R, Goedheer W J and Vanhulsel A 2003 IEEE Trans. Plasma Sci. 31 659-64

[27] Gordillo-Vazquez F J and Albella J M 2004 Plasma Sources Sci. Technol. 13 50-7

[28] Edelberg E A, Perry A, Benjamin N and Aydil E S 1999 J. Vac. Sci. Technol. A 17 506-16

[29] Mizutani N and Hayashi T $2001 \mathrm{~J}$. Vac. Sci. Technol. A 19 1298-303

[30] Mizutani N, Nagata Y, Kubo A and Hayashi T 1998 Rev. Sci. Instrum. 69 1918-19

[31] Sobolewski M A, Wang Y and Goyette A 2002 J. Appl. Phys. $916303-14$

[32] Pecher P and Jacob W 1998 Appl. Phys. Lett. 7331

[33] Baby A, Mahony C M O, Lemoine P and Maguire P D 2011 Plasma Sources Sci. Technol. 20015004

[34] Ropcke J, Lombardi G, Rousseau A and Davies P B 2006 Plasma Sources Sci. Technol. 15 148-68

[35] Mahony C M O, Maguire P D and Graham W G 2005 Plasma Sources Sci. Technol. 14 60-7

[36] Engeln R, Letourneur K G Y, Boogaarts M G H, van de Sanden M C M and Schram D C 1999 Chem. Phys. Lett. 310 405-10

[37] Neyts E, Bogaerts A and Sanden V D 2006 J. Phys. D: Appl. Phys. 39 1948-53

[38] Stoykov S, Eggs C and Kortshagen U 2001 J. Phys. D: Appl. Phys. 34 2160-73

[39] Neyts E, Bogaerts A and Sanden V D 2007 J. Phys. Conf. Ser. 86012020
[40] Hopf C, Jacob W and von Keudell A 2005 J. Appl. Phys. 97094904

[41] http://www.eirene.de/eigen/index.html

[42] von Keudell A, Meier M and Hopf C 2002 Diamond Relat. Mater. 11 969-75

[43] Serdioutchenko A, Moller I and Soltwisch H 2004 Spectrochim. Acta-Part A 60 3311-8

[44] Millar T J, Farquhar P R A and Willacy K 1997 Astron. Astrophys. Suppl. Ser. 121 139-85

[45] Zarrabian M, Leteinturier C and Turban G 1998 Plasma Sources Sci. Technol. 7 607-16

[46] Dagel D J, Mallouris C M and Doyle J R 1996 J. Appl. Phys. 798735

[47] Maier W B 1965 J. Chem. Phys. 42 1790-804

[48] Lembo L J, Helm H and Huestis D L 1989 J. Chem. Phys. 90 5299-308

[49] Morrison N A, William C and Milne W I 2003 J. Appl. Phys. $947031-43$

[50] Hayashi M 2003 NIFS-DATA-72 (Toki, Japan: National Institute of Fusion Science)

[51] Roberto M, Smith H B and Verboncoeur J P 2003 IEEE Trans. Plasma Sci. 31 1292-8

[52] Rusu I A, Popa G and Sullivan J L 2002 J. Phys. D: Appl. Phys. 35 2808-14

[53] Kim J S, Rao M V V S, Cappelli M A, Sharma S P and Meyyappan I 2001 Plasma Sources Sci. Technol. 10 191-204

[54] Phelps A V 1992 J. Phys. Chem. Ref. Data 21 883-97

[55] Lieberman M A and Lichtenberg A J 1994 Principles of Plasma Discharge and Materials Processing (New York: Wiley-Interscience)

[56] Janev R K and Reiter D 2004 Phys. Plasmas 11 780-829

[57] Graham W G, Mahony C M O and Steen P G 2000 Vacuum $563-8$

[58] Mahony C M O 2003 PhD Thesis University of Ulster UK

[59] Rapp D and Englander-Golden P 1965 J. Chem. Phys. 431464

[60] Zheng S H and Srivastava S K 1996 J. Phys. B: At. Mol. Opt. Phys. 29 3235-44

[61] Bera K, Farouk B and Vitello P 2001 J. Phys. D: Appl: Phys. 34 1479-90

[62] Frenklach M and Warnatz J 1987 Combust. Sci. Technol. 51265

[63] Godyak V A and Kolobov V I 1998 Phys. Rev. Lett. 81 369-72

[64] Hopf C et al 2003 Diamond Relat. Mater. 1285

[65] Neyts E et al 2007 Chem. Vapor Depos. 13312

[66] Neyts E et al 2006 J. Appl. Phys. 99014902

[67] Schwarz-Selinger T et al 2003 Vacuum 71361

[68] Benedikt J et al 2010 J. Phys. D: Appl. Phys. 43043001

[69] Hong S et al 2003 Plasma Sources Sci. Technol. 1246

[70] Winter J et al 2009 Plasma Sources Sci. Technol. 18034010

[71] Consoli A et al 2009 Plasma Sources Sci. Technol. 18034004

[72] Cheeseman A et al 2006 J. Phys. Chem. A 1102821

[73] Mankelevich Y et al 2001 Diamond Relat. Mater. 10364

[74] Gould R 1975 J. Chem. Phys. 631825

[75] Mankelevich Y A, Ashfold M N R and Orr-Ewing A J 2007 J. Appl. Phys. 102063310 